\title{
The asymmetric effect of the business cycle on the relation between stock market returns and their volatility
}

\author{
P.N. Smith, S. Sorensen and M.R. Wickens \\ University of York
}

First draft, January 2005

\begin{abstract}
We examine the relation between US stock market returns and the US business cycle for the period 1960 - 2003. We identify two channels in the transmission mechanism. One is through the mean of stock returns via the equity risk premium, and the other is through the volatility of returns. We find that the relation is asymmetric with downturns in the business cycle having a greater negative impact on stock returns than the positive effect of upturns. These results are based on a new model of the relation between returns and their volatility derived from the stochastic discount factor model of asset pricing. This model encompasses CAPM, consumption CAPM and Merton's (1973) inter-temporal CAPM. It is implemented using a multi-variate GARCH-in-mean model with a time-varying conditional heteroskedasticity and correlation structure.
\end{abstract}




\section{Introduction}

The key to understanding how an asset is priced is the relation between its return and its volatility. This relation lies at the centre of most modern theories of asset pricing and much of the associated empirical work. Intuitively, the larger the uncertainty about the future price of an asset, which increases with its volatility, the greater is the required return to compensate for risk. The problem is to specify exactly what the relation between the return and its volatility is.

Both ad hoc and formal models have been used in the literature. These may be linear or nonlinear. The model may seek to explain the asset's return, or its excess return per unit of volatility the Sharpe ratio. Since it is future (or conditional) volatility that is relevant, a volatility forecasting model is required. This may take the form of predicting future volatility from its past, or of using additional, possibly macroeconomic, variables. This has become a common way to link asset-price movements with the macro-economy.

In this paper we use a generalisation of the stochastic discount factor model that encompasses most of the empirical models used in the literature, including CAPM, consumption CAPM, time non-separable utility and Merton's inter-temporal CAPM. The advantage of this approach is that enables us to examine the effect of the business cycle on the stock market within a no-arbitrage framework. Our econometric model is an extension of multivariate GARCH that includes "inmean" effects (to capture risk premia) and asymmetry. We show that there are two channels by which macroeconomic shocks affect stock returns. One is their affect on the mean via the equity risk premium. The other is through the volatility of returns. We find that the effect is asymmetric with downturns in the business cycle having a larger negative effect on stock returns than the positive effect of upturns.

Nominal stock returns also appear to be affected by inflation volatility. In a single factor model, we find that nominal returns are negatively related to the conditional covariance between inflation and nominal returns. This is because the conditional covariance between nominal returns and inflation are generally negative. But in a multi-factor model that also includes output, the conditional covariance between inflation and nominal returns has a positive effect on nominal returns. The reason for the switch in sign is that the conditional covariance between inflation and output is predominantly negative. In other words, positive inflation shocks are associated with negative output shocks. This has an interesting interpretation. Whereas a positive demand shock tends to increase both inflation and output, a negative supply shock tends to increase inflation but reduce output. Thus the observed negative covariance between inflation and output over our data period 1960.1 - 2003.12 indicates that the equity risk premium is dominated by the recesssion of the mid-1970s which was caused by a negative supply shock, the rise in oil-prices. 
The paper is set out as follows. In Section 2 we review the literature on the relation between stock market returns and volatility. In Section 3 we discuss alternative models of the risk premium to CAPM that may explain the impact of the business cycle on stock returns. In Section 4 we consider econometric issues, including how to model macroeconomic effects and asymmetries in the volatility structure in a way that satisfies the condition of no arbitrage. Our results, based on monthly data for the US stock market, are reported in Section 5 and our conclusions are presented in Section 6.

\section{Stock market returns and volatility}

Many papers have examined the effect of stock market volatility of stock returns, most notably, French, Schwert and Stambaugh (1987), Campbell (1987), Harvey (1989), Turner, Startz and Nelson (1989), Baillie and DeGennero (1990) and Glosten, Jagannathan and Runkle (1993). The theoretical basis of these studies is the capital asset pricing model (CAPM) of Sharpe (1964) and Lintner (1965). This can be written as a simple linear relation between the conditional mean and the conditional variance of equity market returns:

$$
E_{t}\left(R_{t+1}^{M}-R_{t+1}^{f}\right)=\alpha+\beta V_{t}\left(R_{t+1}^{M}\right)
$$

where $R_{t+1}^{M}$ is the real return on the market and $R_{t}^{f}$ is the real return on a risk-free asset. Under CAPM, $\alpha=0$ and $\beta$ is the coefficient of relative risk aversion, which may be time-varying. A survey of the results for the US stock market obtained in these studies is provided by Scruggs (1998). He reports that, depending on the measure of market returns, the model of the conditional variance and the method of estimation used, the estimates of $\beta$ have varied from significantly positive to significantly negative.

Broadly, the research into this relation has followed two routes. One involves using increasingly general ways to model conditional volatility. The other employs a more general model of asset pricing than CAPM. Most of the papers surveyed by Scruggs model conditional volatility as a symmetric GARCH process which assumes that the stock market responds similarly to positive and negative shocks. A variant is to include additional variables in the conditional volatility process. Capiello, Engle and Sheppard (2003), for example, using weekly data, find evidence of asymmetries in the conditional variance of most of the developed world's equity indices.

We examine four possible explanations for the asymmetry in the volatility of equity returns. One is the leverage hypothesis due to Black (1976). This states that when the total value of the levered firm falls, the value of its equity decreases relative to the total value of the firm. If equity 
characterises the full risk of a firm, the variance of the equity return should then rise. A price increase should have the opposite effect. Campbell, Lo and MacKinlay (1997) and Schwert (1989) find that this explanation does not fully account for the size of the correlation between the return and its volatility.

A second possible explanation is the volatility-feedback hypothesis of Campbell and Hentschel (1992) which is based on CAPM. They claim that positive shocks to volatility drive down returns. For example, if there is good news about future dividends which raises returns, this will increase the variance of returns and, due to volatility persistence, increase expected future returns. If expected excess returns were perfectly correlated with the conditional variance of the excess return then there would be a decrease in the current stock price which would tend to offset the positive dividend news. If, on the other hand, there is negative news about future dividends we would expect future bad news about dividends and hence expected higher volatility. This would imply a higher expected risk premium and a fall in the price of the stock which would amplify the negative news about future dividends. The volatility-feedback hypothesis therefore requires squared return innovations to be negatively correlated with future volatility.

A third possible explanation for the finding of asymmetry is that it is the result of misspecifying the volatility process. Without using a no-arbitrage asset pricing framework, Kroner and Ng (1998) assume that a multivariate GARCH process with asymmetry is required. Bekaert and $\mathrm{Wu}(2000)$ use a restricted version of the multivariate GARCH process whilst focusing on the risk premium implied by a single-factor CAPM. They use weekly data for the Japanese market portfolio and three leverage-sorted portfolios. They also use a riskless debt model that implies that their specification can divide the potential asymmetry into leverage and volatility feedback effects. Although the leverage effect is not found to be important, there is strong evidence of variance and covariance asymmetry. Bekaert and Wu conclude that their CAPM model generates a time-varying risk premium that, they conjecture, cannot be replicated by general equilibrium models.

A fourth possible explanation is that the information used to form conditional volatility is incomplete. Instead of using an information set based solely on past returns, Lettau and Ludvigson (2002) include other variables. They experiment with several choices, including a proxy for the ratio of consumption-wealth ratio, the log dividend yield and the term spread. All of these variables may be affected by the business cycle. In this way the business cycle can affect returns through their effect on forecasts of volatility. Using the wrong information set may also explain why the estimates of the impact of volatility on returns vary so much. 


\section{The equity risk premium and the business cycle}

In this paper we take a new approach. We examine whether an explanation both for the different results concerning the relation between the mean return and the volatility of returns, and for the finding of asymmetries in the conditional variance, is that a more general theory of asset pricing than CAPM is required. The theory we propose admits the influence of the business cycle on returns, and does so in an asymmetric manner and in a way that satisfies the condition of no-arbitrage.

In Smith and Wickens (2002) we review various alternative empirical asset-pricing models to CAPM. In other papers we have applied this methodology to the stock market (Smith, Sorensen and Wickens (2003)), to the term structure of interest rates (Balfoussia and Wickens (2004)) and to the FOREX market (Smith, Sorensen and Wickens (2005)). We now explain this approach and how it can be modified to incorporate business cycle effects and asymmetries in the response of stock returns to shocks arising both from the stock market and from macroeconomic variables.

\subsection{Modelling returns and volatility using the SDF model}

The inability to hedge against much of the risk arising from the business cycle implies that this risk will be priced in stock market returns, see Shiller (1993). Further, as long horizon returns are partly forecastable, the equity risk premium must be time-varying. And since risk premia arise from conditional variation between returns and economic factors, this suggests that we should study the effects of the business cycle on stock market returns and volatility. It also implies that we should focus on modelling the risk premium. Our model of the relation between returns and volatility is based on the stochastic discount factor (SDF) model of asset pricing.

In the SDF model future real returns are discounted at the stochastic rate $M_{t+1}$. Thus

$$
1=E_{t}\left[M_{t+1}\left(1+R_{t+1}\right)\right]
$$

If $r_{t}=\ln \left(1+R_{t}\right)$ and $m_{t}=\ln M_{t}$ are jointly normally distributed then it can be shown that the expected excess return is

$$
E_{t}\left(r_{t+1}-r_{t}^{f}\right)+\frac{1}{2} V_{t}\left(r_{t+1}-r_{t}^{f}\right)=-\operatorname{Cov}_{t}\left(m_{t+1}, r_{t+1}-r_{t}^{f}\right)
$$

where $r_{t}^{f}=\ln \left(1+R_{t}^{f}\right)$ is known at time $t$. The conditional volatility term on the left-hand side is the Jensen effect, and the term on the right hand-side is the risk premium which must satisfy $\operatorname{Cov}_{t}\left(m_{t+1}, r_{t+1}\right)<0$ for the risk premium to be positive, see Cochrane (2000). It is common to represent $m_{t}$ as a linear function of $n$ factors $z_{i t}$

$$
m_{t}=-\sum_{i=1}^{n} \beta_{i} z_{i t}
$$


implying that the SDF pricing equation is ${ }^{1}$

$$
E_{t}\left(r_{t+1}-r_{t}^{f}\right)+\frac{1}{2} V_{t}\left(r_{t+1}\right)=\sum_{i=1}^{n} \beta_{i} \operatorname{Cov}_{t}\left(z_{i, t+1}, r_{t+1}\right)
$$

Most asset pricing models can be shown to be special cases of the SDF model. These models usually both determine the choice of factors and impose restrictions on the coefficients. For example, the general equilibrium model, consumption CAPM (C-CAPM) due to Breeden (1979) is a single factor SDF model of form

$$
E_{t}\left(r_{t+1}-r_{t}^{f}\right)+\frac{1}{2} V_{t}\left(r_{t+1}\right)=\sigma_{t} \operatorname{Cov}_{t}\left(\Delta c_{t+1}, r_{t+1}\right)
$$

where the factor is the rate of growth of consumption, $c_{t}$ is $\log$ consumption and $\sigma_{t}$ is the coefficient of relative risk aversion.

CAPM gives the asset pricing equations

$$
\begin{aligned}
E_{t}\left(R_{t+1}-R_{t}^{f}\right) & =\beta_{t} E_{t}\left(R_{t+1}^{M}-R_{t}^{f}\right) \\
\beta_{t} & =\frac{\operatorname{Cov}_{t}\left(R_{t+1}^{M}, R_{t+1}\right)}{\operatorname{Var}_{t}\left(R_{t+1}^{M}\right)} \\
E_{t}\left(R_{t+1}^{M}-R_{t}^{f}\right) & =\sigma_{t} \operatorname{Var}_{t}\left(R_{t+1}^{M}\right)
\end{aligned}
$$

Consequently,

$$
E_{t}\left(R_{t+1}-R_{t}^{f}\right)=\sigma_{t} \operatorname{Cov}_{t}\left(R_{t+1}^{M}, R_{t+1}\right)
$$

Since the market return satisfies $1+R_{t+1}^{M}=\frac{W_{t+1}}{W_{t}}$, where $W_{t}$ is wealth, defining $w_{t}=\ln W_{t}$, and noting that $r_{t}=\ln \left(1+R_{t+1}\right) \simeq R_{t}$, we can also express CAPM approximately as

$$
E_{t}\left(r_{t+1}-r_{t}^{f}\right)=\sigma_{t} \operatorname{Cov}_{t}\left(\Delta w_{t+1}, r_{t+1}\right)
$$

In effect, equation (6) is an SDF model in which the market return is acting as its own factor and we have omitted the Jensen effect by not assuming log-normality - while equation (7) reveals that CAPM uses wealth as the factor rather than consumption as in C-CAPM.

In Breeden's C-CAPM it is assumed that the utility function is time separable. If we assume instead that utility is time non-separable, having the Epstein-Zin (1989) CES form

$$
\mathcal{U}_{t}=\left[(1-\beta) C_{t}^{1-\frac{1}{\gamma}}+\beta\left[E_{t}\left(\mathcal{U}_{t+1}^{\frac{1}{1-\sigma}}\right)\right]^{1-\frac{1}{\gamma}}\right]^{\frac{1}{1-\frac{1}{\gamma}}}
$$

where $\beta$ is the discount rate, $\sigma$ is the coefficient of relative risk aversion and $\gamma$ is the elasticity of inter-temporal substitution, we can show that the asset pricing equation becomes

$$
E_{t}\left(r_{t+1}-r_{t}^{f}\right)+\frac{1}{2} V_{t}\left(r_{t+1}\right)=\frac{1-\gamma \sigma}{1-\gamma} \operatorname{Cov}_{t}\left(r_{t+1}^{M}, r_{t+1}\right)+\frac{1-\sigma}{1-\gamma} \operatorname{Cov}_{t}\left(\Delta c_{t+1}, r_{t+1}\right)
$$

\footnotetext{
${ }^{1}$ Note that as $r_{t}^{f}$ is known at time $t, V_{t}\left(r_{t+1}-r_{t}^{f}\right)=V_{t}\left(r_{t+1}\right)$ and $\operatorname{Cov}_{t}\left(m_{t+1}, r_{t+1}-r_{t}^{f}\right)=\operatorname{Cov}_{t}\left(m_{t+1}, r_{t+1}\right)$.
} 
When $r_{t+1}$ is the market return $r_{t+1}^{M}$

$$
E_{t}\left(r_{t+1}^{M}-r_{t}^{f}\right)+\frac{1}{2} V_{t}\left(r_{t+1}^{M}\right)=\frac{1-\gamma \sigma}{1-\gamma} \operatorname{Var}_{t}\left(r_{t+1}^{M}\right)+\frac{1-\sigma}{1-\gamma} \operatorname{Cov}_{t}\left(\Delta c_{t+1}, r_{t+1}^{M}\right)
$$

see Smith, Sorensen and Wickens (2003). Thus, compared with the SDF model equation (4), the coefficient on the volatility of the market return is no longer restricted. In order to obtain such an unrestricted form from the SDF model we would need to assume that the market return is one of the factors.

Scruggs (1998) and Scruggs and Glabadanidis (2001) are an exception in not using a model related to the SDF model. They base their empirical work on the general equilibrium model of Merton (1973), namely inter-temporal CAPM (ICAPM), derived from the continuous-time utility of wealth function $J\left(W_{t}, F_{t}, t\right)$ where $W_{t}$ is wealth and $F_{t}$ is a variable describing the state of investment opportunities in the economy. In equilibrium, this gives the relation

$$
E_{t}\left(r_{t+1}^{M}-r_{t}^{f}\right)=\left[\frac{-J_{W W} W}{J_{W}}\right] \operatorname{Var}_{t}\left(r_{t+1}^{M}\right)+\left[\frac{-J_{W F}}{J_{W}}\right] \operatorname{Cov}_{t}\left(F_{t+1}, r_{t+1}^{M}\right)
$$

where for risk averse investors, $\left[\frac{-J_{W W} W}{J_{W}}\right]>0$ is the coefficient of relative risk aversion. If the coefficients are assumed to be constant then this is similar to the SDF model in which the market return is used as a factor. It is not exactly the same as the SDF model as the coefficient on the conditional variance is not $-\frac{1}{2}$. We note, however, that the Epstein-Zin model also relaxes the restriction on the coefficient on the volatility of the market return.

The SDF model may be written in a number of different ways. For example, equation (3) can be re-written as

$$
\begin{aligned}
E_{t}\left(r_{t+1}-r_{t}^{f}\right)+\frac{1}{2} V_{t}\left(r_{t+1}-r_{t}^{f}\right) & =-S D_{t}\left(r_{t+1}-r_{t}^{f}\right) S D_{t}\left(m_{t+1}\right) \operatorname{Cor}_{t}\left(m_{t+1}, r_{t+1}-r_{t}^{f}\right) \\
& =S D_{t}\left(r_{t+1}\right) \sum_{i=1}^{n} \beta_{i} S D_{t}\left(z_{i, t+1}\right) \operatorname{Cor}_{t}\left(z_{i, t+1}, r_{t+1}\right)
\end{aligned}
$$

where $S D_{t}($.$) denotes the conditional standard deviation and C o r_{t}($.$) the conditional correlation.$ This is a non-linear relation between an asset's return and its volatility which is attentuated by the volatility of the factors and their conditional correlations with the asset return. The SDF model satisfies the principle of no-arbitrage. It also shows the form in which additional variables should be included in the asset pricing equation, i.e. as terms involving their conditional covariances with the asset return. We also note that the coefficients $\beta_{i}$ are unrestricted; they can be positive or negative as long as the overall risk premium is positive.

A different way of expressing the SDF model is in terms of the excess return per unit of volatility, the Sharpe ratio:

$$
\frac{E_{t}\left(r_{t+1}-r_{t}^{f}\right)}{S D_{t}\left(r_{t+1}\right)}=-\frac{1}{2} S D_{t}\left(r_{t+1}\right)+\sum_{i=1}^{n} \beta_{i} S D_{t}\left(z_{i, t+1}\right) \operatorname{Cor}_{t}\left(z_{i, t+1}, r_{t+1}\right)
$$


This is the form of model used by Lettau and Ludvigson (2002). It is clear that the Sharpe ratio will be small when macroeconomic volatility is low, the correlations between macroeconomic variables and stock returns are close to zero, or the macroeconomic variables are not significantly priced in the stock market. In the special case where the conditional correlations are constant the Sharpe ratio becomes a linear function in the conditional standard deviations. The model coefficients then measure the effect on the Sharpe ratio of a unit of volatility in the factors.

Another way of writing the SDF model brings out its connections with CAPM. This is

$$
\begin{aligned}
E_{t}\left(r_{t+1}-r_{t}^{f}\right) & =\left[-\frac{1}{2}+\sum_{i=1}^{n} \beta_{i} \gamma_{i, t}\right] V_{t}\left(r_{t+1}\right) \\
\gamma_{i, t} & =\frac{\operatorname{Cov}_{t}\left(z_{i, t+1}, r_{t+1}\right)}{V_{t}\left(r_{t+1}\right)}
\end{aligned}
$$

This shows that CAPM is a special case of the SDF model in which the coefficient on the conditional variance is constrained to be constant, rather than time varying and non-linearly dependent on the factors. Moreover, in general, this coefficient cannot be interpreted as the coefficient of relative risk aversion.

We conclude that a general representation of the market return that encompasses all of the models above is given by

$$
E_{t}\left(r_{t+1}^{M}-r_{t}^{f}\right)=\beta_{0} V_{t}\left(r_{t+1}^{M}\right)+\sum_{i=1}^{n} \beta_{i} \operatorname{Cov}_{t}\left(z_{i, t+1}, r_{t+1}^{M}\right)
$$

and this can be written in several different ways. With two further modifications, this is the model that we shall use in this paper.

The first modification is required because all of the models above assume the existence of a real risk-free asset whereas, in practice, only a nominal risk-free asset is available. ${ }^{2}$ The SDF pricing equation, equation (2), can be re-written using nominal returns as

$$
1=E_{t}\left[M_{t+1}\left(1+I_{t+1}^{M}\right) \frac{P_{t}^{c}}{P_{t+1}^{c}}\right]
$$

where $I_{t}^{M}$ is the nominal market rate of return and $P_{t}^{c}$ is the consumer price index. It can be shown that the SDF asset-pricing equation for nominal returns is

$$
E_{t}\left(i_{t+1}^{M}-i_{t}^{f}\right)+\frac{1}{2} V_{t}\left(i_{t+1}^{M}\right)=-\operatorname{Cov}_{t}\left(m_{t+1}, i_{t+1}^{M}\right)+\operatorname{Cov}_{t}\left(\pi_{t+1}, i_{t+1}^{M}\right)
$$

where $i_{t}^{M}=\ln \left(1+I_{t}^{M}\right), i_{t}^{f}$ is the nominal risk-free rate and $\pi_{t+1}=\ln \left(P_{t+1}^{c} / P_{t}^{c}\right)$ defines the inflation rate. Thus, if we work with nominal returns, we must also include inflation as a factor. Our general model then becomes

\footnotetext{
2 The nearest to a real risk-free return is the one-period return on an index-linked bond. In the US, index linked bonds are not available for one period (month) and are not perfectly indexed for inflation.
} 


$$
E_{t}\left(i_{t+1}^{M}-i_{t}^{f}\right)=\phi_{0} V_{t}\left(i_{t+1}^{M}\right)+\phi_{1} \operatorname{Cov}_{t}\left(\pi_{t+1}, i_{t+1}^{M}\right)+\sum_{2}^{n} \phi_{i} \operatorname{Cov}_{t}\left(z_{i, t+1}, i_{t+1}^{M}\right)
$$

We now have one further modification to make.

\subsection{Including business cycle effects}

Schwert (1989) conducted one of the first detailed studies of the effects of the business cycle on stock returns. ${ }^{3}$ He investigated whether the volatility of real economic activity is a determinant of stock return volatility on the grounds that common stocks reflect claims on the future profits of corporations. The findings were, however, that the volatility of industrial production growth did not help to predict stock market volatility; on the contrary, stock market volatility was able to predict output volatility. Schwert concluded that stock market volatility and the volatility of industrial production is higher during recessions. He also examined the relation between stock market return and inflation using Producer Price Index (PPI) inflation as a factor but found that inflation volatility does not help predict future stock return volatility as it is not much affected by recessions. In addition, he considered the effect of volatility in the rate of growth of money. He found this to be a little more volatile during recessions, but it too was unable to predict stock market volatility. Taken together, Schwert's results do not resolve the puzzle of why stock prices are so highly volatile when macroeconomic variables are not.

The emphasis since Schwert's work has been to examine stock market behaviour using CCAPM in which consumption is the sole factor of production. The focus of most of this research has been the equity premium puzzle, see Campbell (2003) for a survey and also Smith, Sorensen and Wickens (2003). The general finding, whether calibration analysis or conventional econometric estimation is used, is that consumption does not vary enough to explain stock market volatility and so requires an implausibly large value of the coefficient of relative risk aversion to match the volatility of the equity premium. Among the new findings in Smith, Sorensen and Wickens (2003) were the significance of both the consumption and inflation conditional covariances with the stock return, implying that both are priced sources of risk.

Scruggs (1998) and Scruggs and Glabadanidis (2001) are also an exception to the general run of results in the literature. Using ICAPM, their estimating equation is

$$
r_{t+1}^{M}=\lambda_{0}+\lambda_{1} \operatorname{Var}_{t}\left(r_{t+1}^{M}\right)+\lambda_{2} \operatorname{Cov}_{t}\left(F_{t+1}, r_{t+1}^{M}\right)+e_{t+1}
$$

\footnotetext{
3 Earlier work by Campbell and Shiller (1988a, 1988b) showed that the log stock price reflects the expectation of future cash flows, future interest rates and the future excess return. If macroeconomic data contains information about expected future cash flows or expected future discount rates, potentially it can explain the time-variation in monthly stock market returns.
} 
where $r_{t}^{M}$ and $F_{t}$ (they choose the return on long-term US Treasury bonds) are specified as EGARCH(1,1) processes with constant correlation. Scruggs and Glabadanidis (2001) use an asymmetric EGARCH model. $\lambda_{0}$ is found to be insignificant, $\lambda_{1}$ is generally positive and significant and $\lambda_{2}$ is negative and significant. These findings also suggest the presence of time-varying risk factors.

In this paper we re-consider Schwert's analysis of business cycle effects within a no-arbitrage framework based on a generalisation of the SDF model through a suitable choice of the factors $z_{t}$. This generates two channels through which the business cycle may affect stock returns. First, if the mean return is dependent on the conditional volatility of returns, as in CAPM and ICAPM, and returns and the factors have a joint conditional distribution, then the conditional covariance between returns and the factors allows volatility in the factors to affect volatility in the returns and hence the returns themselves. Second, conditional covariation between the returns and the factors affects returns through the risk premium. Asymmetries in the transmission mechanism may also impact through these two channels.

We consider three macroeconomic factors: industrial production, inflation and money growth. The risk premum is greatest when returns are expected to be low. Low returns occur during recessions, hence we expect returns to have a positive correlation with output. This correlation may also be time varying. The relation between returns and inflation is less clear-cut. Through the Phillips curve relation, macroeconomic theory tends to associate recession with lower inflation. This implies a positive correlation between returns and inflation. However, this is true only when the recession is due to a demand shock. A recession due to a supply shock is more likely to have higher than lower inflation, implying a negative correlation between returns and inflation. This suggests that the correlation between returns and inflation is very likely to be time varying. This is exactly what we find. Our third macroeconomic variable is the rate of growth of narrow money which we expect to have a positive correlation with returns.

In addition to helping determine the risk premum, time-varying volatility in the macroeconomic variables may have an impact on the volatility of returns. Higher output, inflation and money growth volatility is likely to be associated with higher volatility in returns.

\section{The econometric framework}

We wish to estimate the joint distribution of the stock market return and the macroeconomic factors subject to the restriction that the conditional mean of the returns equation satisfies the no-arbitrage condition and to allowing business-cycle shocks to impact asymmetrically.

Consider first the multivariate GARCH-in-mean (MGM) model. The advantage of a mul- 
tivariate over the univariate GARCH model used by, for example, Glosten, Jagannathan and Runkle (1993), is that the variance of each of the dependent variables can be predicted by lagged values of conditional variances of all the variables and lagged covariances between all variables, and lagged squared residuals and cross products of residuals (variance and covariance news). A disadvantage of multivariate GARCH models is that they are highly parameterised. In an attempt to reduce the number of parameters more restrictive formulations have been proposed. One of these is the constant correlation model of Bollerslev-(1990). Assuming a constant correlation structure over time is, however, a strong assumption and is normally unwarranted in asset pricing. A second simpler alternative is the dynamic conditional correlation model of Engle (2002) which allows for time-variation in the conditional correlations. This model is, however, less well suited to multivariate GARCH-in-mean models due to estimation problems arising from the "in-mean" effect. Moreover, the assumption of a constant conditional correlation does not seem plausible for asset-pricing models. A third alternative is the Factor ARCH model of Engle and Ng (1990) which allows the factors to drive the conditional covariance matrix.

Rather than use any of these more restictive models, we prefer the more general BEKK model proposed by Engle and Kroner (1995). This allows unrestricted time-varying variances and correlations, and the inclusion of observable macroeconomic factors, see Smith and Wickens (2002) and Smith, Sorensen and Wickens (2003). The BEKK model can also be modified to include asymmetries - see Kroner and Ng (1998) - and allows second moment in-mean effects to represent the risk premium. As a result we obtain the econometric model

$$
\mathbf{Y}_{t+1}=\mathbf{A}+\sum_{i=1}^{p} \mathbf{B}_{i} \mathbf{Y}_{t+1-i}+\sum_{j=1}^{N_{1}} \boldsymbol{\Phi}_{j} \mathbf{H}_{[1: N, j], t+1}+\boldsymbol{\epsilon}_{t+1}
$$

where $\mathbf{Y}_{t+1}$ is an $N \times 1$ vector of dependent variables in which the first $N_{1}$ elements are assumed to be the excess returns, $\mathbf{A}$ is an $N \times 1$ vector, the $\mathbf{B}_{i}$ and $\boldsymbol{\Phi}_{j}$ and $\boldsymbol{\Psi}$ matrices are $N \times N$, $H_{[1: N, j], t+1}$ is the $N \times 1 j^{t h}$ column of the conditional variance covariance matrix. The first $N_{1}$ equations satisfy the restrictions imposed by no arbitrage. The risk premia are given by the first $N_{1}$ columns of $\sum_{j=1}^{N_{1}} \boldsymbol{\Phi}_{j} H_{[1: N, j], t+1}$. Thus, the associated $\boldsymbol{\Phi}_{j}$ matrices are unrestricted except for the $j^{\text {th }}$ element which is $-\frac{1}{2}$. The corresponding rows of $B_{j}$ are restricted to zero. The remaining equations have no "in-mean" effect but otherwise are unrestricted. $\mathbf{\Upsilon}_{k, t+1}$ is an indicator variable taking the value of 1 in specified periods and zero otherwise.

We define $Y_{t+1}=\left\{i_{s, t+1}^{e} \pi_{t+1} \Delta m_{t+1} \Delta y_{t+1}\right\}$. Thus, there is a single return $i_{s, t+1}^{e}$ (the excess return of the stock market), and there are three macroeconomic factors: $\pi_{t+1}$ is the inflation rate, $\Delta m_{t+1}$ is the rate of growth of narrow money M1 and $\Delta y_{t+1}$ is the growth rate of industrial production. Consequently, the first row of $\Phi_{1}$ must satisfy the no-arbitrage condition. The other 
elements of $\Phi_{1}$ are restricted to equal zeros. We use a vector auto-regression of order $1(\mathrm{p}=1)$ implying that the model can be written

$$
\mathbf{Y}_{t+1}=\mathbf{A}+\mathbf{B} \mathbf{Y}_{t}+\mathbf{\Phi} \mathbf{H}_{[1: N, 1], t+1}+\mathbf{\Theta} \Upsilon_{1987: 10, t+1}+\boldsymbol{\epsilon}_{t+1}
$$

Only the first row of $B$ is restricted to be zero; the remaining elements of $B$ are unrestricted.

$\Upsilon_{1987: 10, t+1}$ is a dummy variable which is included to take account of the stock market crash of October 1987. The excess return in this month is clearly an outlier and is almost certainly not explicable by our theory of asset pricing, see Schwert (1998). Thus it takes the value of 1 for $t+1$ corresponding to October 1987 and zero otherwise.

We examine whether business-cycle shocks impact on stock returns asymmetrically through the specification of the error term $\epsilon_{t+1}$. We assume that the error term displays conditional heteroskedasticity. In other words, the covariance matrix of $\epsilon_{t+1}$, and hence the volatility of returns, is partly forecastable and may respond differently to positive and negative business cycle shocks.

We specify the error term as

$$
\boldsymbol{\epsilon}_{t+1}=\mathbf{H}_{t+1}^{\frac{1}{2}} \mathbf{u}_{t+1}, \quad \mathbf{u}_{t+1} \sim \mathcal{D}\left(0, \mathbf{I}_{4}\right)
$$

where, in order to allow for excess kurtosis in the error term, we assume the data have a joint t-distribution (see, for instance, Hafner (2001)). $I_{4}$ is the identity matrix of dimension four. We assume that the conditional covariance matrix $H_{t+1}$ is an asymmetric version of the BEKK model (ABEKK) defined by

$$
\mathbf{H}_{t+1}=\mathbf{C C}^{\top}+\mathbf{D}\left(\mathbf{H}_{t}-\mathbf{C} \mathbf{C}^{\top}\right) \mathbf{D}^{\top}+\mathbf{E}\left(\boldsymbol{\epsilon}_{t} \boldsymbol{\epsilon}_{t}^{\top}-\mathbf{C C}^{\top}\right) \mathbf{E}^{\top}+\mathbf{G}\left(\boldsymbol{\eta}_{t} \boldsymbol{\eta}_{t}^{\top}-\overline{\mathbf{C C}}^{\top}\right) \mathbf{G}^{\top},
$$

where the asymmetry is due to the term in $\eta_{t}=\min \left[\epsilon_{t}, 0\right]$. The bar over $C C^{\top}$ indicates that the appropriate correction is made since $\mathrm{E}_{t}\left(\eta_{t} \eta_{t}^{\top}\right) \neq C C^{\top} .{ }^{4}$ The eigenvalues of

$$
(\mathbf{D} \otimes \mathbf{D})+(\mathbf{E} \otimes \mathbf{E})+(\overline{\mathbf{G} \otimes \mathbf{G}}),
$$

must lie inside the unit circle for the BEKK system to be stationary. $\otimes$ is the Kronecker product.

Equation (17) is estimated using the Quasi-Maximum Likelihood estimator proposed by Bollerslev and Wooldridge (1992). For numerical reasons, we may want to scale our variables so that the variables have the same sample variances. The scaled version can be written

$$
\mathbf{Y}_{t+1}^{*}=\mathbf{A}^{*}+\mathbf{B}^{*} \mathbf{Y}_{t}^{*}+\boldsymbol{\Phi}^{*} \mathbf{H}_{[1: N, 1], t+1}^{*}+\mathbf{\Theta}^{*} \Upsilon_{t+1}+\boldsymbol{\epsilon}_{t+1}^{*}
$$

\footnotetext{
${ }^{4} \overline{\mathbf{C C}}^{\top}$ is obtained by multiplying the diagonal elements of $\mathbf{C C}^{\top}$ by $\frac{1}{2}$ and the off-diagonal elements by $\frac{1}{4}$.
} 
with $Y_{t+1}^{*}=\Gamma Y_{t+1}, \epsilon_{t+1}^{*}=\Gamma \epsilon_{t+1}$ and $H_{t+1}^{*}=\Gamma H_{t+1} \Gamma^{\top}$. The original coefficient matrices can be recovered as $A=\Gamma^{-1} A^{*}$ and $B=\Gamma^{-1} B^{*} \Gamma$. Since we are interested in matching the variances of the data, $\Gamma$ will be diagonal. For example, the first dependent variable is the excess return on the stock market and we scale inflation so that it has the same variance. As result, the element in the diagonal of $\Gamma$ takes the value $\sqrt{\frac{\operatorname{Var}\left(i_{s, t+1}^{e}\right)}{\operatorname{Var}\left(\pi_{t+1}\right)}}$, where $\operatorname{Var}(\cdot)$ is the sample variance. ${ }^{5}$ The conditional covariance matrix in the scaled model can be written

$$
\mathbf{H}_{t+1}^{*}=\mathbf{C}^{*} \mathbf{C}^{* \top}+\mathbf{D}^{*}\left(\mathbf{H}_{t}^{*}-\mathbf{C}^{*} \mathbf{C}^{* \top}\right) \mathbf{D}^{* \top}+\mathbf{E}^{*}\left(\boldsymbol{\epsilon}_{t}^{*} \boldsymbol{\epsilon}_{t}^{* \top}-\mathbf{C}^{*} \mathbf{C}^{* \top}\right) \mathbf{E}^{* \top}+\mathbf{G}^{*}\left(\boldsymbol{\eta}_{t}^{*} \boldsymbol{\eta}_{t}^{* \top}-\overline{\mathbf{C}^{*} \mathbf{C}^{* \top}}\right) \mathbf{G}^{* \top}
$$

where $\eta_{t}^{*}=\min \left[\epsilon_{t}^{*}, 0\right]$. It follows directly that $C=\Gamma^{-1} C^{*}, D=\Gamma^{-1} D^{*} \Gamma, E=\Gamma^{-1} E^{*} \Gamma$ and $G=\Gamma^{-1} G^{*} \Gamma$. All of the results reported below are the original coefficients obtained by transforming back to the unscaled model.

The risk premium is given by the first row of

$$
\phi_{t}=\mathbf{\Phi} \mathbf{H}_{[1: N, 1], t+1}
$$

This can be decomposed in different ways. One decomposition is into the components associated with each of the factors. Thus we can write the total risk premium as

$$
\phi_{t}=\phi_{\text {excess return }, t}+\phi_{\text {inflation }, t}+\phi_{\text {money }, t}+\phi_{\text {output }, t}
$$

A second decomposition allows us to determine the importance of asymmetries. $H_{t+1}$, as defined by equation (18), has four components, and hence can be re-written as

$$
\mathbf{H}_{t+1}=\mathbf{H}_{0}+\mathbf{H}_{1, t+1}+\mathbf{H}_{2, t+1}+\mathbf{H}_{3, t+1}
$$

Pre-multiplying by $\boldsymbol{\Phi}$ gives the decomposition

$$
\phi_{t}=\phi_{0}+\phi_{1 t}+\phi_{2 t}+\phi_{3 t}
$$

where $\phi_{3 t}$ is the component of the risk premium due to asymmetries. $\phi_{1 t}$ is the component due to autoregressive effects and $\phi_{2 t}$ is the component due to $\mathrm{ARCH}$ effects.

In estimating this model we make an assumption regarding the initial value of the conditional covariance matrix. One possibility is to set the starting value equal to the unconditional covariance matrix of the dependent variables. Another is to perform the unrestricted vector auto-regression from equation (20) and use the estimated covariance matrix of the residuals. A third possibility

\footnotetext{
5 Note that scaling the variables may affect the correction terms. We do not scale the excess return and so the Jensen term should still equal $\frac{1}{2} \mathrm{~V}_{t}\left(i_{s, t+1}^{e}\right)$.However, we scale inflation and so the correction for working with nominal returns should not be $\operatorname{Cov}_{t}\left(i_{s, t+1}^{e}, \pi_{t+1}\right)$ but $\frac{\sqrt{\operatorname{Var}\left(\pi_{t+1}\right)}}{\sqrt{\operatorname{Var}\left(i_{s, t+1}^{e}\right)}} \operatorname{Cov}_{t}\left(i_{s, t+1}^{e}, \pi_{t+1}\right)$.
} 
is to estimate the starting values, noting from equation (18), that $\mathrm{E}\left(H_{t+1}\right)=C C^{\top}{ }^{6}{ }^{6}$ All estimations were carried out using each of the starting values, but the final values were virtually identical.

\section{The results}

\section{$5.1 \quad$ Models estimated}

The general model to be estimated can be written

$$
E_{t}\left(i_{s, t+1}^{e}\right)+\frac{1}{2} V_{t}\left(i_{s, t+1}^{e}\right)=\mathbf{b}^{\top} \operatorname{Cov}_{t}\left(i_{s, t+1}^{e}, \mathbf{Y}_{t+1}\right)+\theta \Upsilon_{1987: 10, t+1}
$$

The individual models differ in their choice of $\mathbf{Y}_{t+1}$. Model 1 is CAPM and takes the form

$$
\mathrm{E}_{t}\left(\mathrm{i}_{s, t+1}^{e}\right)+\frac{1}{2} \mathrm{~V}_{t}\left(\mathrm{i}_{s, t+1}^{e}\right)=\gamma \mathrm{V}_{t}\left(\mathrm{i}_{s, t+1}^{e}\right)+\operatorname{Cov}_{t}\left(\pi_{t+1}, \mathrm{i}_{s, t+1}^{e}\right)+\theta \Upsilon_{1987: 10, t+1}
$$

Model 7 removes the restriction that the conditional covariance with inflation has a unit coefficient and is used to test CAPM. Model 2 and Model 3 are more general than Model 1 but are not associated with any particular theory. Model 2 is a version of ICAPM with three macroeconomic variables. If any of these macroeconomic variables are significantly priced then this would serve as a rejection of CAPM. Model 3 prices only the macroeconomic variables and excludes the conditional variance of the market return. Model 4, Model 5 and Model 6 price each of the macroeconomic variables individually and enable us to evaluate the total contribution of each individual macroeconomic variable.

\subsection{The data}

The data are monthly for the US over the period 1960:01 to 2003:12. The stock market returns are the value-weighted return on all NYSE, AMEX and NASDAQ stocks. The risk-free rate is the one-month US Treasury Bill rate. ${ }^{7} \quad$ The macroeconomic data are the index of industrial production, CPI inflation and the rate of growth of M1. These data are obtained from the Federal Reserve Bank of St. Louis.

In Table 1 we report descriptive statistics for these data. The excess stock market return has little autocorrelation but displays negative skewness, excess kurtosis, non-normality and autocorrelation both in the squared returns and in the absolute returns. This indicates that the volatility

\footnotetext{
6 This starting value is consistent.

7 This is available from the homepage of Kenneth French, http://mba.tuck.dartmouth.edu/pages/faculty/ken.french/.
} 
of returns is partly predictable and there is evidence of asymmetries in the volatility process. It suggests that an $\mathrm{ARCH}$ process with asymmetries may be able to represent these data.

Inflation has substantial autocorrelation, has positive skewness, does not show excess kurtosis, but is non-normal. There is autocorrelation in squared inflation and in the absolute value of inflation. Money growth is very like inflation except that its absolute values have less autocorrrelation. Industrial production closely resembles stock-market returns except that it has stronger first-order autocorrelation in its squares and absolute values. This uni-variate evidence supports the use of a multi-variate asymmetric ARCH model.

\subsection{Model estimates}

The estimates of the various no-arbitrage models with asymmetric effects are reported in Table 2. Model 1 (CAPM) has the lowest explanatory power as measured both by the log-likelihood and by the percentage of the variation in the excess return (adjusted for the Jensen effect and 1987 outlier) explained by variations in the risk premium. The mean residual is significantly differently from zero. CAPM constrains the coefficient of the conditional covariance with inflation to be unity. Model 7 shows that this restriction is invalid and suggests that inflation has a stronger impact on returns than CAPM allows.

Model 2 (ICAPM/Epstein-Zin) and Model 3 (SDF) fit almost equally well as Models 1 and 7. In Model 2 three variables are significantly priced: the market return, and two macroeconomic variables, inflation and industrial production. The variability of the implied risk premium for Model 2 is more than 11 times higher than that of Model 1, moreover, its residuals are considerably closer to zero than those of Model 1. The 1987 dummy is only significant in Model 1.

In Model 3 (SDF) all three macroeconomic variables are significantly priced. The significance of money growth in Model 3 but not in Model 2 is a reflection of the effects of correlation between the explanatory variables, the conditional covariance terms. The unconditional correlation between the conditional covariance of money growth with the market return and the conditional variance of the market return is 0.65 . This suggests that money growth may only be significant due to omitting the market return, which is a more significant variable. Nonetheless, Model 3 explains a larger share of the variation in the excess return than Model 2 and its mean residual is closer to zero.

Models 4-6 are SDF models with only a single macroeconomic factor. Inflation is the most significantly priced, followed by industrial production; money growth on its own is not significantly priced. This is a further sign of the effects of correlation between the conditional covariance terms.

These results support previous findings that the volatility of the US stock market return 
significantly explains the return - or, put another way, the market return is a priced factor. They also show clearly that CAPM can be rejected in favour of a more general asset-pricing model that includes additional macroeconomic factors. It appears that both inflation and output growth are significantly priced, but money growth does not seem to have further useful information. We therefore omit the asset-pricing models involving money growth from our subsequent analysis and concentrate mainly on Model 2. Money growth is not, however, eliminated entirely from the model; it is retained as part of the information set and so has its own equation. In this way, money is still a conditioning variable and so is able to help forecast the conditional covariance matrix of the other variables. This is justified by the significance of money in the multivariate GARCH process.

\subsection{Estimates for Model 2}

The full set of estimates of Model 2 are reported in Table 3. There are four equations in the model. The first equation is for the excess return and is restricted to satisfy the condition of no-arbitrage. The other three equations have no "in-mean" effects, but do have VAR effects. These are captured in the matrix B. Apart from significant own lags, the lagged excess return is strongly significant in the money equation, and lagged inflation is significant in the output equation.

Turning to the GARCH process, the matrices $\mathbf{D}$ and $\mathbf{E}$ are highly significant. Although the diagonal terms are the most significant, there are significant off-diagonal effects too so that each variable seems to significantly explain all of the others. For example, an increase in the variance of output growth in the previous period predicts there will be an increase in the variance of the excess return on the stock market in the following period, and vice-versa. There is, therefore, a strong interaction between the stock market and business cycle volatility. There are similar interactions between the stock market and inflation and, interestingly, between output and inflation. A higher inflation variance predicts higher future output variability.

We are particularly interested in the results on asymmetry, which is captured by matrix $\mathbf{G}$. We find that the variances of both stock market returns and industrial production growth show strong asymmetries, and is greatest for output. The negative signs imply that negative own shocks have a greater impact on the variance than positive shocks. In particular, negative business cycle shocks have a larger impact on output than positive shocks. There is also strong evidence of the business cycle impacting asymmetrically on the stock market as negative output shocks are found to have a larger impact on stock returns than positive shocks. In other words, business-cycle downturns affect the stock market more than upturns.

There is also evidence of negative shocks to stock returns increasing inflation volatility but 
positive shocks having no effect. And we find that negative shocks to money growth tend to have an extra affect on the variance of excess returns. Similar results are obtained for Model 3.

\subsection{The equity risk premium}

\subsubsection{Estimates}

In Figure 1 we plot the risk premia for Models 1 and 2, together with the excess stock market return. The shaded areas are recessions as defined by the NBER. The risk premium for Model 2 clearly varies over time much more than that of Model 1 . We note that the risk premium for Model 1 is positive in each period. This is because in CAPM the risk premium is proportional to the conditional variance of the market return. Whilst the risk premium for Model 2 is mainly positive, from time to time it is negative, as in 1973-4 when it is significantly negative. We note from Figure 2 that the risk premia for Models 4-6 display many more periods when the risk premium is negative. The fact that the risk premium for Model 2 is less prone to being negative indicates that the conditional covariances are negatively correlated and offset each other. This demonstrates that the simplifying assumption of a constant correlation over time is not appropriate for modelling the joint distribution of the excess return and the macroeconomic variables.

Table 4, which reports the autocorrelation coefficients of the risk premia for the six models, shows that Model 1 has the most persistent risk premium, and Models 4-6 have the least persistent and most volatile. The persistence of the risk premia for Models 2 and 3 are similar, and similar to that for Model 6 for which output is the sole factor. This suggests that the business cycle is the dominant factor determining equity risk.

For most of the time the periods when the risk premium in Model 2 is largest tend to be periods of recession. This is further support for the importance of asymmetries. Model 3 is similar. A notable exception is the recession of 1973-4 when, as already mentioned, the risk premium is negative. The explanation for this is particularly interesting and we discuss this below.

In Figure 3 we plot the risk premium for Model 2 together with the conditional volatilities for returns and the three macroeconomic factors. The highest correlation is that between the risk premium and the volatility of output. This is evidence in support of the importance of the business cycle in explaining the equity risk premium. We also note that the correlation between the risk premium and the volatility of returns is much lower, suggesting that a simple model relating returns to their volatility does not perform well.

The asymmetric effects on the risk pemium of good and bad news may be judged from Figure 4 where the three time-varying components of the risk premium $\phi_{1 t}, \phi_{2 t}$ and $\phi_{3 t}$ are plotted. The contribution of asymmetries to the risk premium is given by $\phi_{3 t}$ in equation (22). It is clear that 
$\phi_{1 t}$, the autoregressive component, is the most important, but next is $\phi_{3 t}$. Asymmetries seem to have their greatest effect on the risk premium in recessions. This is consistent with the notion that risk averse investors are more concerned about recessions than booms.

\subsubsection{Macroeconomic sources of risk}

In Table 5 we report the recession dates and in Table 6 we provide some summary statistics comparing recessions with periods not in recesssion. The most striking findings are the mean stock returns and output growth rates during recession and elsewhere. These suggest a strong business cycle effect on stock returns. In contrast, we note that the correlations between returns and the macroeconomic variables are not very different in recessions from non-recessions. The interest in this result is that we find that the conditional correlation coefficient of returns and output is strongly time varying, suggesting that this is masked using unconditional correlations.

A necessary condition for the macroeconomic factors to be priced sources of time-varying risk is that they display time-varying volatility. In Figure 4 the conditional volatility of each factor is plotted together with the risk total premium. The volatility of the macroeconomic variables clearly varies through time and tends to be greatest during recessions when the risk premium is also at its height. Inflation and output volatility seem to have been lower in the last twenty years than in the more turbulent 1970's, whereas money growth volatility has recently returned to the high levels of 1970's after a period of tranquility. Maccini and Pagan (2003) have suggested that the decline in output volatility is a reflection of volatility following a square root process. A contributing factor is that there has been a reduction in negative shocks to output in the most recent period.

Another necessary condition for the macroeconomic factors to be priced is that they are correlated with the excess return. In Figure 5 we plot the time-varying correlations between the market excess return and the macroeconomic factors. This shows the strength of the correlations and the fact that they vary over time. The conditional correlation between the excess market return and inflation is predominantly negative, unlike the correlations with output and money growth.

Combining this information gives the contribution of each factor to the total risk premium. This is plotted in Figure 6. We find that the contribution of the market return is positive, but that of inflation is nearly always negative, whilst the contribution of output fluctuates in sign, being largely negative in the 1970's and positive in the 1980's, but becoming negative again during the late 1990's recession. To gain more understanding of what is happening, in Figure 7 we show for Model 2 the time-varying correlations between certain macroeconomic factors and the correlation with the risk premium. During the 1973-1975 recession, when the risk premium 
is strongly negative, Figure 3 shows that inflation volatility was high. Figure 6 reveals that its contribution to the risk premium was then at its most negative, and Figure 7 shows that the correlation between returns and inflation was significantly negative. Figure 7 also reveals that during this recession, the correlation between inflation and output are strongly negative, reflecting the fact that the recession was caused by a supply shock - the rise in oil and other commodity prices - and not a demand shock. There is another strong negative correlation in 1979 when there was a second oil price shock. During later recessions inflation and output are positively correlated which is consistent with the recessions being due instead to negative demand shocks.

Two alternative conclusions are suggested by this evidence. The first is that the 1973-4 recession was a period of risk taking. This is, however, implausible. If we rule out a preference for risk and assume that risk premia are strictly non-negative, then a second explanation is that the theory is unable to cope with risk arising from negative supply shocks. It appears that during these recessions the stock market return was driven so low that, even if the risk premium did increase, it is obscured by the abnormal severity of the fall in returns.

These findings reveal many other things too. For example, periods with high risk premia are associated with periods of very low correlation between money and output suggesting that negative correlation between money and output shocks coincide with more risky stock market returns. At the end of the recessions and shortly after, the risk premium tends to decline implying that unfavourable economic conditions that make the stock market more risky. The recessions of 1973-75 and 1979-81 had a negative correlation between inflation and output and so were started by a supply shock, but were followed by a strong positive correlation between inflation and output, suggesting a demand stimulus was given to the economy to counteract the recession.

It is also worth observing that this evidence undermines an assumption that underlies a lot of work in macroeconomics that inflation and output are always positively related and so can be modelled through a Phillips curve.

\subsubsection{Implications for CAPM}

We began this study by observing that the key to understanding how an asset is priced is the relation between its return and its volatility. As a result, it seems obvious to use of CAPM to study the relation. We have shown, however, that the standard formulation of CAPM is not general enough and that the evidence provides strong support for the SDF model. We have also noted in equation (13) that we can interpret the SDF model as a more general version of CAPM in which the coefficient on the conditional volatility of returns is time varying.

In Figure 8 we plot this coefficient, unsmoothed and smoothed. It is very striking how volatile 
the coefficient is. This reveals how inadequate standard CAPM is in explaining the relation between returns and volatility. We also note that although the coefficient is positive most of the time, in the 1973-75 recession it is highly negative. This shows once more the problem that standard asset pricing models have in explaining the behaviour of stock returns during that period.

\section{Conclusion}

The main finding in this paper is a strong asymmetric relation between the US business cycle and the US stock market over the period 1960 to 2003. Downturns in the business cycle have a greater negative impact on stock returns than the positive effect of upturns.

In contrast to the pioneering work of Schwert and later purely empirically-based approaches in the literature, our analysis was conducted within an explicit no-arbitrage framework of the relation between returns and their volatility that was derived from the SDF model of asset pricing. This enabled us to derive a formal relation between returns and the business cycle via the equity risk premium. We showed that the SDF model is capable of encompassing a number of different asset-pricing theories, including CAPM, consumption CAPM with either time separable or time non-separable preferences, and Merton's inter-temporal CAPM in which the market return is a factor. Our model also embraces that of Lettau and Ludvigson. An advantage of the SDF model over general equilibrium models is that we can relate the equity risk premium to the business cycle rather than to consumption. We are also able to investigate the potential effects of other macroeconomic variables such as inflation and money growth. Our results support an SDF model with three priced factors: output, inflation and the stock market return.

Another feature of our analysis is that we model the joint distribution of stock returns and observable macroeconomic variables using a multivariate GARCH model with conditional covariance "in-mean" effects to represent the risk premium. This is a more general approach than that used hitherto in the literature as it neither excludes conditional covariance effects in the mean, nor does it restrict the conditional correlation structure to be constant over time. Further, the conditional covariances are not restricted to be linear functions of the factors as in the Vasicek model. These generalisations strongly influence our new findings. In addition to the three priced factors, we find that money growth should also be included in the joint distribution.

In our model, there are two channels through which the business cycle may affect stock returns. There is a mean effect coming via the equity risk premium, and there is a volatility effect coming through the conditional covariance matrix. All three macroeconomic variables operate significantly through the volatility of returns, but only output and inflation have a significant effect on the mean return. 
As a result of allowing for time-varying correlation we discovered a difference in the effects on stock returns between a recession caused by negative supply shocks and one caused by negative demand shocks. We found that the correlation between output and inflation was negative during the recessions caused by the two oil price shocks of the 1970's, thereby indicating negative supply shocks. In contrast, the earlier and later recessions were associated with a positive correlation between output and inflation, suggesting that these recessions were caused by negative demand shocks. Such a time-varying correlation between output and inflation raises doubts about the large body of evidence on the Phillips curve which typically assumes a constant positive correlation.

We also draw attention to a finding that casts doubt on our version of the SDF model of the equity risk premium. In 1974, during the recession caused by the first oil price shock, the fall in stock returns is so large that the estimated risk premium becomes negative in order to explain such extremely negative returns. This indicates that although our model of the equity premium gives a reasonably satisfactory account of the equity risk premium in normal times, it is unable to deal with an extreme event such as this. It is common in modelling asset prices to suppose that a mixture of distributions is required to account for all of the observations. In effect, it is assumed that certain extreme values are generated by a different distribution. This is the logic behind the inclusion of jump variables. Our results provide new evidence supporting this practice.

We began this study by observing that the key to understanding how an asset is priced is the relation between its return and its volatility. Our results have shown that CAPM, the model mainly used in empirical work on this issue, is strongly rejected by the data in favour of one in which, in effect, the coefficient on the conditional volatility of returns is highly time varying and may be explained by macroeconomic factors via an SDF model. 


\section{References}

Baillie, R. and R.P. Degennaro, "Stock Returns and Volatility", Journal of Financial and Quanttitative Analysis, Vol. 25, No. 2, June, 1990

Balfoussia, C and M.R. Wickens, "Macroeconomic Sources of Risk in the Term Structure", CESifo Working Paper 1329, November 2004

Bekaert, G. and G. Wu, "Asymmetric Volatility and Risk in Equity Markets", The Review of Financial Studies, Vol. 13, No. 1, p. 1-42, Spring, 2000

Breeden, D., "An Intertemporal Asset Pricing Model with Stochastic Consumption and Investment Opportunities", Journal of Financial Economics, Vol. 7, Issue 3, p. 265-296, 1979

Black, F., "Studies of Stock Price Volatility Changes", In Proceedings of the 1976 Meetings of the Business and Economic Statistics Section

Bollerslev, T., "Modelling the Coherence in Short-Run Nominal Exchange Rates: A Multivariate Generalised ARCH Model", The Review of Economics and Statistics, Vol. 74, No. 3, p. $498-505,1990$

Bollerslev, T. and J.M. Wooldridge, "Quasi-Maximum Likelihood Estimation and Inference in Dynamic Models with Time-Varying Covariances", Econometric Reviews, Vol. 11, No. 2, p. $143-172,1992$

Campbell, J., "Stock Returns and the Term Structure", Journal of Financial Economics, Vol. 18, p. 373-399, 1987

Campbell, J.Y. and L. Hentschel, "No News is Good News", Journal of Financial Economics, Vol. 31, Issue 3, p. 281-318, June, 1992

Campbell, J.Y. and R. Shiller, "The Dividend-Price Ratio and Expectations of Future Dividends and Discount Factors", Review of Financial Studies, Vol. 1, Issue 3, p. 195-227, 1988a

Campbell, J.Y. and R. Shiller, "Stock Prices, Earnings and Expected Dividends", The Journal of Finance, Vol. 43, No. 3, p. 661-676, June, 1988b

Campbell, J.Y., Lo, A.W. and A.C. MacKinlay, The Econometrics of Financial Markets, 1997, Princeton University Press, Second printing

Capiello, L., Engle R.F. and K. Sheppard, "Asymmetric Dynamics in the Correlations of Global Equity and Bond Returns", Working Paper No. 204, 2003

Cochrane, J., Asset Pricing, Princeton Univeristy Press, 1st Edition, 2000

Engle, R.F., "Dynamic Conditional Correlation - A Simple Class of Multivariate GARCH Models", Journal of Business and Economic Statistics, Vol. 17, No. 5, 2002

Engle, R.F. and K.K. Kroner, "Multivariate Simultaneous Generalised ARCH", Econometric Theory, Vol. 11, No. 1, p. 122-150, 1995

Engle, R.F. and V.K. Ng, "Asset Pricing with a Factor-ARCH Covariance Structure - Empirical Evidence for Treasury Bills", Journal of Econometrics, Vol. 45, p. 213-237, 1990

Epstein, L.G. and S.E. Zin, "Substitution, Risk Aversion, and the Temporal Behavior of Consumption and Asset Returns: A Theoretical Framework", Econometrica, Vol. 57, No. 4, p. $937-969,1989$ 
French, K.R., Schwert, G.W. and R.F. Stambaugh, "Expected Stock Return and Volatility", Journal of Financial Economics, Vol. 19, p. 3-30, 1987

Glosten, L.R., Jagannathan R. and D.E. Runkle, "On the Relation between the expected value and the volatility of the nominal excess returns on stocks", Journal of Finance, Vol. 48, p. $1779-1801,1993$

Harvey, C., "Time-Varying Conditional Covariances in Tests of Asset Pricing Models", Journal of Financial Economics, Vol. 24, p. 289-317, 1989

Kroner, K.F. and V.K. Ng, "Modelling Asymmetric Comovements of Asset Returns", The Review of Financial Studies, Vol. 11, No. 4, p. 817-844, 1998

Lettau, M. and S.C. Ludvigson, "Measuring and Modeling Variation in The Risk-Return Tradeoff ", 2002, Manuscript, Chapter prepared for Handbook of Financial Econometrics, 2002

Lintner, J., "The Valuation of Risk Assets and the Selection of Risky Investments in Stock Portfolios and Capital Budgets", Review of Economics and Statistics, Vol. 47, p. 13-37, 1965

Maccini, L.J. and A. Pagan, "Exploring the Role of Inventories in the Business Cycle", Manuscript, Australian National University, 2003

Merton, R., "An Intertemporal Capital Asset Pricing Model", Econometrica, Vol. 41, No. 5, September, p. 867-887, 1973

Schwert, G. W., "Why Does Stock Market Volatility Change Over Time ?", Journal of Finance, Vol. 44, No. 5, p. 1115-1153, December, 1989

Schwert, G. W., "Stock Market Volatility: Ten Years after the Crash", For Brooking-Wharton Conference on Financial Institutions, Available from http://schwert.ssb.rochester.edu/gws.htm, 1998

Scruggs, J.T., "Resolving the Puzzling Intertemporal Relation between the Market Riskpremium and Conditional Market Variance: A Two-Factor Approach", Journal of Finance, Vol. 53, No. 2, p. 575-603, April, 1998

Scruggs, J.T. and P. Glabadanidis, "Risk Premia and the Dynamic Covariance Between Stock and Bond Returns", EFA 2001 Barcelona Meetings, March 21st, 2001

Sharpe, W., "Capital Asset Prices: A theory of Market Equilibrium under Conditions of Risk", Journal of Finance, Vol. 19, No. 3, September, p. 425-442, 1964

Shiller, R, Macromarkets, Oxford University Press, 1st Edition, 1993

Smith, P.N. and M.R. Wickens, "Asset pricing with observable stochastic discount factors", Journal of Economic Surveys, Vol. 16, p. 397-446, 2002

Smith, P.N., Sorensen, S. and M.R. Wickens, "Macroeconomic Sources of Equity Risk", University of York, Discussion Paper 13/03, 2003

Smith, P.N., Sorensen, S. and M.R. Wickens, "Macroeconomic Sources of FOREX Risk", Manuscript, University of York, 2005

Smith, P.N., Sorensen, S. and M.R. Wickens, "An Asset Market Integration Test Based on Observable Macroeconomic Stochastic Discount Factors", in P. Sinclair (ed), Exchange Rates, Capital Flows and Policy, Routledge, 2004 
Turner, C.M., Startz, R. and C.R. Nelson, "A Markov Model of Heteroskedasticity, Risk, and Learning in the Stock Market", NBER Working Paper 2818, 1989 
Table1 : Descriptive Statistics

\begin{tabular}{lcccc}
\hline & $i_{s, t+1}^{e}$ & $\pi_{t+1}$ & $\Delta m_{t+1}$ & $\Delta y_{t+1}$ \\
\hline \hline Mean & 4.46 & 4.27 & 5.02 & 3.04 \\
Std. Dev & 53.46 & 3.62 & 6.02 & 9.00 \\
Skewness & -0.71 & 1.03 & 0.12 & -0.59 \\
Kurtosis & 5.79 & 4.70 & 4.08 & 5.92 \\
Normality & $59.91^{* *}$ & $90.10^{* *}$ & $21.52^{* *}$ & $72.36^{* *}$ \\
\hline$\rho\left(x_{t}, x_{t-1}\right)$ & 0.07 & 0.66 & 0.52 & 0.37 \\
$\rho\left(x_{t}, x_{t-2}\right)$ & -0.05 & 0.60 & 0.33 & 0.29 \\
$\rho\left(x_{t}, x_{t-3}\right)$ & -0.01 & 0.56 & 0.33 & 0.26 \\
$\rho\left(x_{t}, x_{t-4}\right)$ & -0.01 & 0.54 & 0.31 & 0.21 \\
$\rho\left(x_{t}, x_{t-5}\right)$ & 0.07 & 0.54 & 0.33 & 0.08 \\
$\rho\left(x_{t}, x_{t-6}\right)$ & -0.03 & 0.54 & 0.34 & 0.10 \\
\hline$\rho\left(x_{t}^{2}, x_{t-1}^{2}\right)$ & 0.05 & 0.66 & 0.53 & 0.27 \\
$\rho\left(x_{t}^{2}, x_{t-2}^{2}\right)$ & 0.12 & 0.62 & 0.34 & 0.14 \\
$\rho\left(x_{t}^{2}, x_{t-3}^{2}\right)$ & 0.15 & 0.59 & 0.31 & 0.14 \\
$\rho\left(x_{t}^{2}, x_{t-4}^{2}\right)$ & 0.08 & 0.56 & 0.23 & 0.05 \\
$\rho\left(x_{t}^{2}, x_{t-5}^{2}\right)$ & 0.10 & 0.57 & 0.22 & -0.04 \\
$\rho\left(x_{t}^{2}, x_{t-6}^{2}\right)$ & 0.09 & 0.58 & 0.26 & 0.07 \\
\hline$\rho\left(|x|_{t},|x|_{t-1}\right)$ & 0.05 & 0.63 & 0.44 & 0.31 \\
$\rho\left(|x|_{t},|x|_{t-2}\right)$ & 0.06 & 0.61 & 0.26 & 0.13 \\
$\rho\left(|x|_{t},|x|_{t-3}\right)$ & 0.07 & 0.54 & 0.22 & 0.10 \\
$\rho\left(|x|_{t},|x|_{t-4}\right)$ & 0.03 & 0.52 & 0.23 & 0.05 \\
$\rho\left(|x|_{t},|x|_{t-5}\right)$ & 0.02 & 0.55 & 0.20 & -0.04 \\
$\rho\left(|x|_{t},|x|_{t-6}\right)$ & 0.02 & 0.52 & 0.21 & 0.04 \\
\hline$\rho($.$) is the correlation and x_{t}$ is the relevant column variable \\
\hline
\end{tabular}

Note: Two stars as superscipt indicates that normality is rejected using $0.99 \mathrm{CV}$. x refers to variable in first row of table. 
Table 2. Estimates of Models 1 to 7

\begin{tabular}{|c|c|c|c|c|c|c|c|}
\hline & M1 & M2 & M3 & M4 & M5 & M6 & M7 \\
\hline$V_{t}\left(i_{t+1}^{e}\right)$ & $\begin{array}{l}3.57 \\
(3.75)\end{array}$ & $\begin{array}{l}11.14 \\
(2.53)\end{array}$ & & & & & $\begin{array}{l}10.49 \\
(3.15)\end{array}$ \\
\hline $\operatorname{Cov}_{t}\left(i_{t+1}^{e}, \pi_{t+1}\right)$ & 1 & $\begin{array}{c}780.28 \\
(2.98)\end{array}$ & $\underset{(2.10)}{533.99}$ & $\begin{array}{c}-663.67 \\
(4.10)\end{array}$ & 1 & 1 & $\underset{(3.95)}{1093.17}$ \\
\hline $\operatorname{Cov}_{t}\left(i_{t+1}^{e}, \Delta m_{t+1}\right)$ & & $\begin{array}{l}-18.49 \\
(0.16)\end{array}$ & $\underset{(2.51)}{496.42}$ & & $\begin{array}{c}1342.50 \\
(2.82)\end{array}$ & & \\
\hline $\operatorname{Cov}_{t}\left(i_{t+1}^{e}, \Delta y_{t+1}\right)$ & & $\begin{array}{l}-312.09 \\
(3.71)\end{array}$ & $\begin{array}{l}-341.34 \\
(3.38)\end{array}$ & & & $\begin{array}{c}-353.60 \\
(4.33)\end{array}$ & \\
\hline$\Upsilon_{1987: 10, t+1}$ & $\begin{array}{l}-0.27 \\
(2.39)\end{array}$ & $\begin{array}{l}-0.27 \\
(0.82)\end{array}$ & $\begin{array}{c}-0.2791 \\
(0.84)\end{array}$ & $\begin{array}{l}-0.29 \\
(1.13)\end{array}$ & $\begin{array}{l}-0.29 \\
(1.90)\end{array}$ & $\begin{array}{l}-0.26 \\
(1.28)\end{array}$ & $\begin{array}{l}-0.28 \\
(1.00)\end{array}$ \\
\hline$\nu$ & $\begin{array}{l}10.83 \\
(4.83) \\
\end{array}$ & $\begin{array}{r}9.90 \\
(5.36) \\
\end{array}$ & $\begin{array}{l}10.05 \\
(5.38) \\
\end{array}$ & $\begin{array}{l}9.61 \\
(5.27) \\
\end{array}$ & $\begin{array}{l}9.47 \\
(5.24) \\
\end{array}$ & $\begin{array}{l}9.84 \\
(5.36) \\
\end{array}$ & $\begin{array}{l}8.92 \\
(5.57) \\
\end{array}$ \\
\hline Log Likelihood & -2130.5 & -2109.2 & -2112.0 & -2120.5 & -2124.2 & -2117.5 & -2118.8 \\
\hline LR Risk Premium & 8.60 & 7.54 & 6.79 & 9.02 & 7.58 & 5.69 & 8.79 \\
\hline Average Residual & -2.27 & -1.34 & -0.60 & -2.74 & -1.41 & 0.46 & -2.60 \\
\hline Risk Share (\%) & 0.59 & 11.90 & 12.11 & 8.70 & 11.60 & 11.80 & 11.20 \\
\hline
\end{tabular}

Note: Share of risk $=100 \cdot \operatorname{Var}\left(\phi_{t}\right) / \operatorname{Var}\left(i_{t+1}^{e}+\frac{1}{2} V_{t}\left(i_{t+1}^{e}\right)-\widehat{\theta} \Upsilon_{1987: 10, t+1}\right)$

$\nu=$ degrees of freedom. LR: Long Run or average. Absolute t-statistics in parenthesis. 
Table 3. Estimates of Model 2

$$
\begin{aligned}
\mathbf{Y}_{t+1} & =\mathbf{A}+\mathbf{B} \mathbf{Y}_{t}+\mathbf{\Phi} \mathbf{H}_{[1: N, 1], t+1}+\mathbf{\Theta} \Upsilon_{1987: 10, t+1}+\boldsymbol{\epsilon}_{t+1} \\
\boldsymbol{\epsilon}_{t+1} & =\mathbf{H}_{t+1}^{\frac{1}{2}} \mathbf{u}_{t+1}, \quad \mathbf{u}_{t+1} \sim \mathcal{D}\left(0, \mathbf{I}_{4}\right) \\
\mathbf{H}_{t+1} & =\mathbf{C C}^{\boldsymbol{\top}}+\mathbf{D}\left(\mathbf{H}_{t}-\mathbf{C} \mathbf{C}^{\boldsymbol{\top}}\right) \mathbf{D}^{\top}+\mathbf{E}\left(\boldsymbol{\epsilon}_{t} \boldsymbol{\epsilon}_{t}^{\top}-\mathbf{C C}^{\boldsymbol{\top}}\right) \mathbf{E}^{\boldsymbol{\top}}+\mathbf{G}\left(\boldsymbol{\eta}_{t} \boldsymbol{\eta}_{t}^{\top}-\overline{\mathbf{C C}}^{\boldsymbol{\top}}\right) \mathbf{G}^{\boldsymbol{\top}}
\end{aligned}
$$

$$
\begin{aligned}
& \widehat{A}=\left[\begin{array}{c}
0 \\
0.0967 \\
(5.85) \\
0.1306 \\
(4.42) \\
0.2792 \\
(5.80)
\end{array}\right], \quad \widehat{\Phi}=\left[\begin{array}{llll}
11.14 & 780.28 & -18.49 & -312.09 \\
(2.53) & (3.02) & (0.16) & (3.71) \\
0 & 0 & 0 & 0 \\
0 & 0 & 0 & 0 \\
0 & 0 & 0 & 0
\end{array}\right] \\
& \widehat{B}=\left[\begin{array}{cccc}
0 & 0 & 0 & 0 \\
0.0016 & 0.6621 & 0.0193 & -0.0107 \\
(0.70) & (20.44) & (1.19) & (0.87) \\
0.0142 & 0.0535 & 0.6007 & -0.0062 \\
(4.22) & (0.86) & (15.78) & (0.26) \\
\underset{0.0009}{0.16)} & -0.2150 & 0.0475 & 0.2793 \\
(2.24) & (0.92) & (6.83)
\end{array}\right] \\
& \widehat{D}=\left[\begin{array}{cccc}
0.5589 & 2.4030 & 3.5705 & 2.7721 \\
(4.46) & (1.67) & (3.29) & (3.87) \\
0.0233 & 0.7501 & -0.1550 & -0.1349 \\
(3.12) & (8.58) & (2.08) & (2.50) \\
0.0362 & -0.1029 & -0.5781 & 0.1246 \\
(1.88) & (0.32) & (6.07) & (1.95) \\
0.1483 & -1.1940 & 0.2977 & -0.3907 \\
(4.26) & (2.57) & (1.68) & (3.07)
\end{array}\right] \\
& \widehat{E}=\left[\begin{array}{cccc}
-0.0085 & -0.4953 & -0.7441 & 0.0315 \\
(0.24) & (1.13) & (1.49) & (0.15) \\
-0.0029 & 0.3002 & -0.0100 & -0.0290 \\
(1.09) & (6.55) & (0.30) & (1.85) \\
-0.0035 & -0.0568 & 0.5315 & -0.1017 \\
(0.72) & (0.53) & (7.27) & (2.65) \\
-0.0170 & -0.0489 & -0.2386 & 0.0131 \\
(2.12) & (0.33) & (2.46) & (0.20)
\end{array}\right] \\
& \widehat{G}=\left[\begin{array}{cccc}
-0.0661 & -1.5521 & -1.3589 & 0.0762 \\
(1.91) & (1.66) & (3.24) & (0.34) \\
-0.0119 & 0.0736 & -0.0202 & 0.0575 \\
(3.76) & (0.80) & (0.80) & (2.27) \\
-\underset{0.0021}{0.19)} & -0.2081 & 0.0060 & -0.0347 \\
-0.97) & (0.04) & (0.55) \\
-0.0117 & 0.2254 & -0.1171 & 0.5432 \\
(0.92) & (0.74) & (0.96) & (6.66)
\end{array}\right]
\end{aligned}
$$




$$
\begin{aligned}
100 \cdot \widehat{C} & =\left[\begin{array}{cccc}
4.8236 & 0 & 0 & 0 \\
(6.74) & & & \\
0.0017 & 0.2369 & 0 & 0 \\
(0.07) & (8.30) & & \\
0.0435 & 0.0469 & 0.4657 & 0 \\
(1.08) & (1.15) & (6.88) & \\
0.1404 & 0.0458 & -0.0382 & 0.7290 \\
(1.57) & (0.58) & (0.64) & (6.99)
\end{array}\right] \\
1200^{2} \cdot \widehat{C} \widehat{C}^{\prime}= & {\left[\begin{array}{cccc}
3350.40 & 1.18 & 30.24 & 97.50 \\
1.18 & 8.08 & 1.61 & 1.58 \\
30.24 & 1.61 & 31.82 & -1.38 \\
97.50 & 1.58 & -1.38 & 79.87
\end{array}\right] }
\end{aligned}
$$

Table 4. Autocorrelation coefficients for risk premia

\begin{tabular}{cccccccc}
\hline & $\rho_{1}$ & $\rho_{2}$ & $\rho_{3}$ & $\rho_{4}$ & $\rho_{5}$ & $\rho_{6}$ & $\rho_{12}$ \\
\hline \hline$\phi_{t}^{\text {Model 1 }}$ & 0.98 & 0.96 & 0.93 & 0.91 & 0.88 & 0.85 & 0.65 \\
$\phi_{t}^{\text {Model 2 }}$ & 0.43 & 0.59 & 0.31 & 0.30 & 0.09 & 0.09 & -0.10 \\
$\phi_{t}^{\text {Model 3 }}$ & 0.33 & 0.58 & 0.26 & 0.27 & 0.11 & 0.07 & -0.12 \\
$\phi_{t}^{\text {Model 4 }}$ & 0.73 & 0.61 & 0.42 & 0.23 & 0.09 & -0.03 & -0.23 \\
$\phi_{t}^{\text {Model 5 }}$ & 0.57 & 0.58 & 0.41 & 0.32 & 0.20 & 0.17 & -0.13 \\
$\phi_{t}^{\text {Model 6 }}$ & 0.26 & 0.60 & 0.18 & 0.35 & 0.05 & 0.20 & -0.07 \\
$\phi_{t}^{\text {Model 7 }}$ & 0.64 & 0.70 & 0.50 & 0.47 & 0.28 & 0.26 & -0.09 \\
\hline
\end{tabular}

Note: Absolute t-statistics in parenthesis. 
Table 5: Recession dates and number of observations

\begin{tabular}{ccccccc}
\hline 60:03-61:05 & $69: 11-70: 10$ & $73: 11-75: 03$ & $80: 01-80: 07$ & $81: 07-82: 11$ & $90: 07-91: 03$ & $01: 03-01: 11$ \\
\hline \hline 15 & 12 & 17 & 7 & 17 & 9 & 9 \\
\hline
\end{tabular}

Total no. obs. $=86$

Table 6. Summary statistics comparing periods of recession with other periods

\begin{tabular}{l|cccc}
\hline & log return & inflation & money & ind. prod. \\
\hline \hline Mean in recessions & -6.5147 & 5.9593 & 5.0598 & -7.3957 \\
Mean elsewhere & 6.4664 & 3.8649 & 5.0537 & 4.9132 \\
Correlation with log returns in recessions & 1 & -0.1417 & 0.0920 & 0.0190 \\
Correlation with log returns elsewhere & 1 & -0.1394 & 0.0723 & 0.0480 \\
Mean conditional SD during recessions & 54.9312 & 3.4322 & 5.7111 & 10.6250 \\
Mean conditional SD deviation elsewhere & 48.9321 & 2.4689 & 4.9801 & 7.4919 \\
\hline \hline Mean contributions to risk prem. in recessions & 28.6471 & -16.7822 & -0.2983 & -0.6827 \\
Mean contributions to risk prem. elsewhere & 22.7963 & -9.2757 & -0.1772 & -6.3054 \\
\hline
\end{tabular}


Figure 1: Risk premia for Models 1-2 and excess return

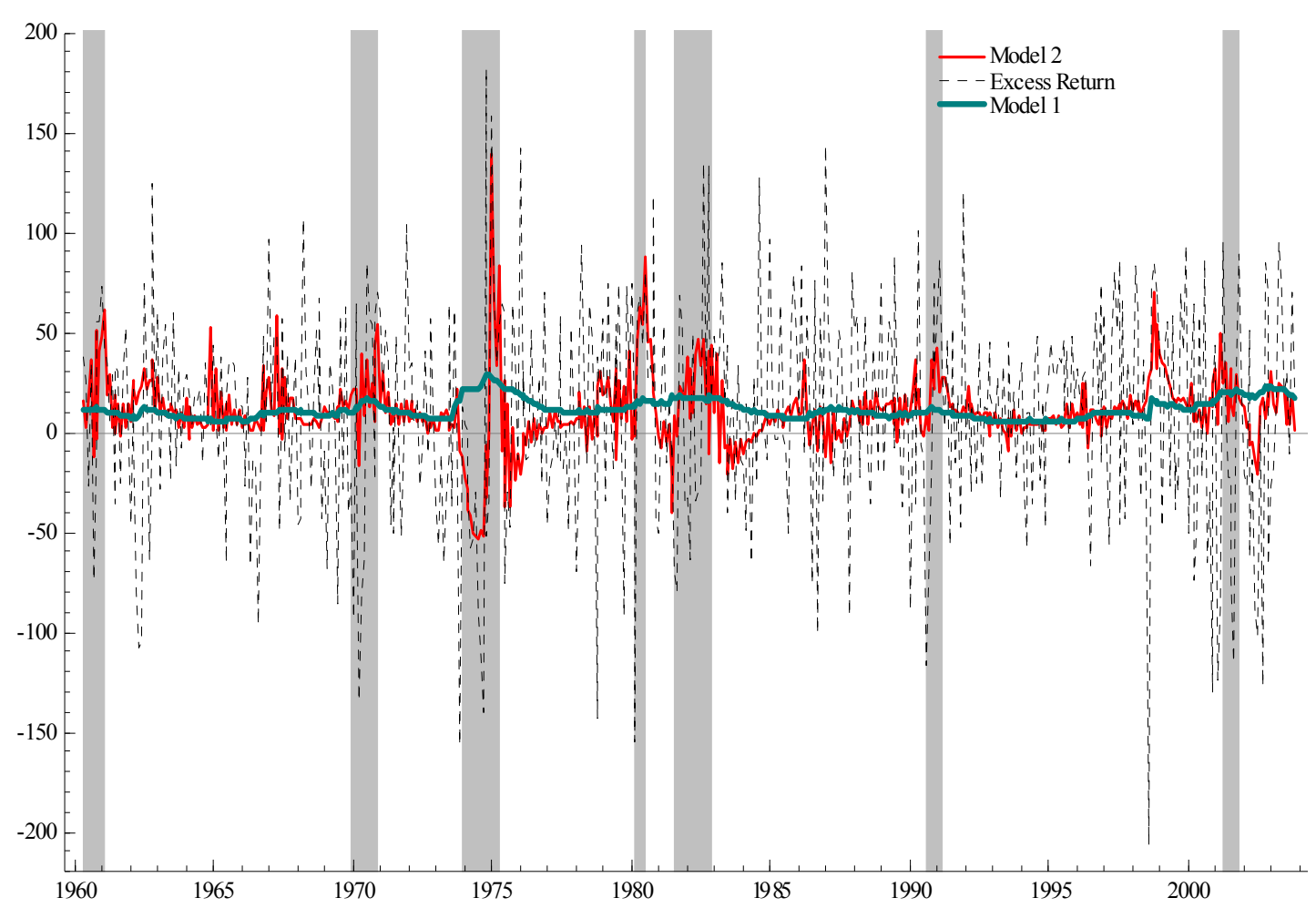

Notes: The excess return is net of the Jensen effect and the October 1987 dummy. The data are measured in annualised percentages. Shaded areas are recessions as defined by the NBER. 
Figure 2: Risk premia for Models 4-6

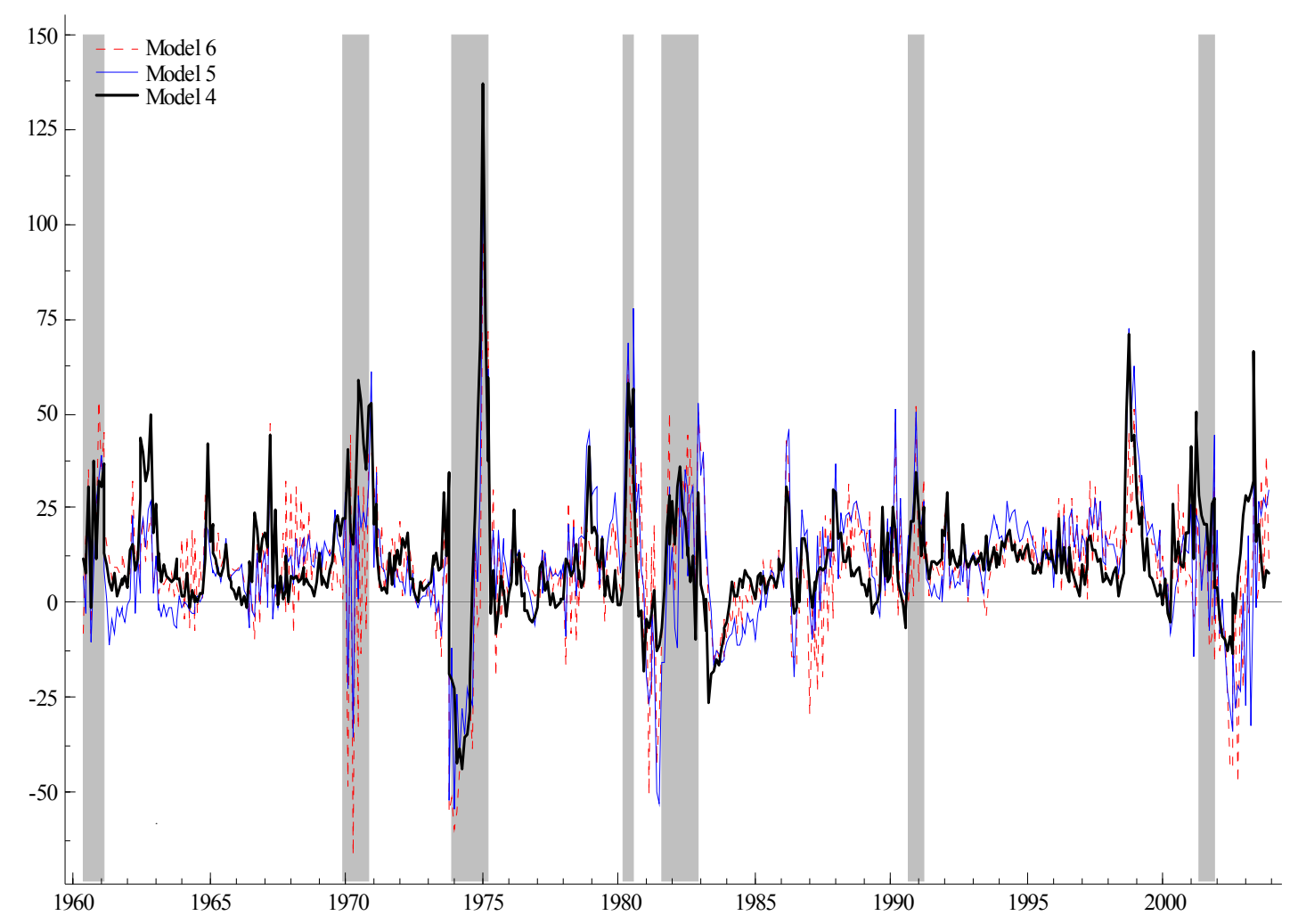

Notes: see Figure 1. 
Figure 3: The risk premium and the conditional variances of the factors
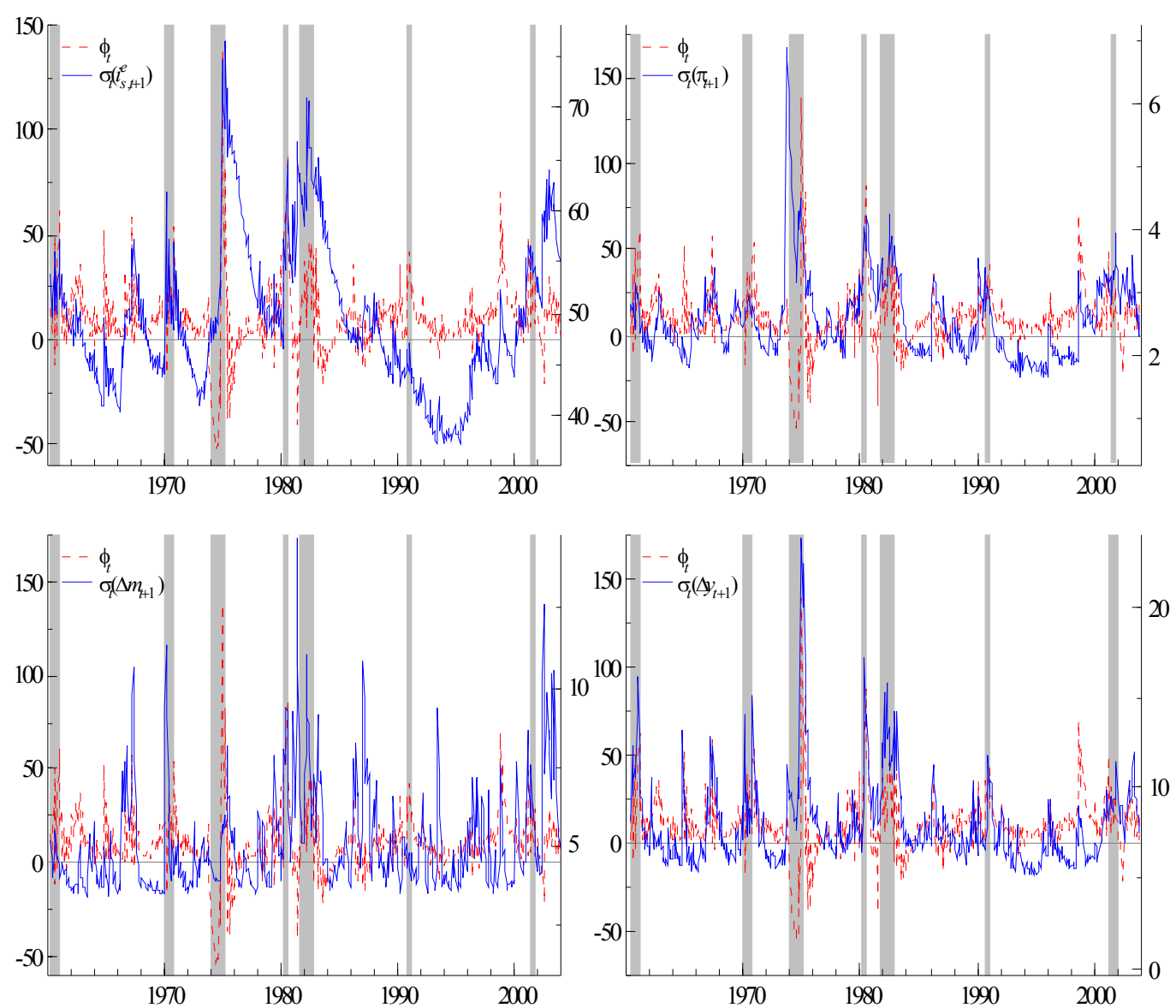

Notes: the scale for the risk premium is on the left axis and that for the correlations is on the right. All are measured in annualised percentages. The unconditional correlations are $\rho\left(\phi_{t}, \sigma_{t}\left(i_{t+1}^{e}\right)\right)=0.19$, $\rho\left(\phi_{t}, \sigma_{t}\left(\pi_{t+1}\right)\right)=0.04, \rho\left(\phi_{t}, \sigma_{t}\left(\Delta m_{t+1}\right)\right)=0.07, \rho\left(\phi_{t}, \sigma_{t}\left(\Delta y_{t+1}\right)\right)=0.31$. Shaded are recessions as defined by the NBER. 
Figure 4: The contribution to risk of asymmetries
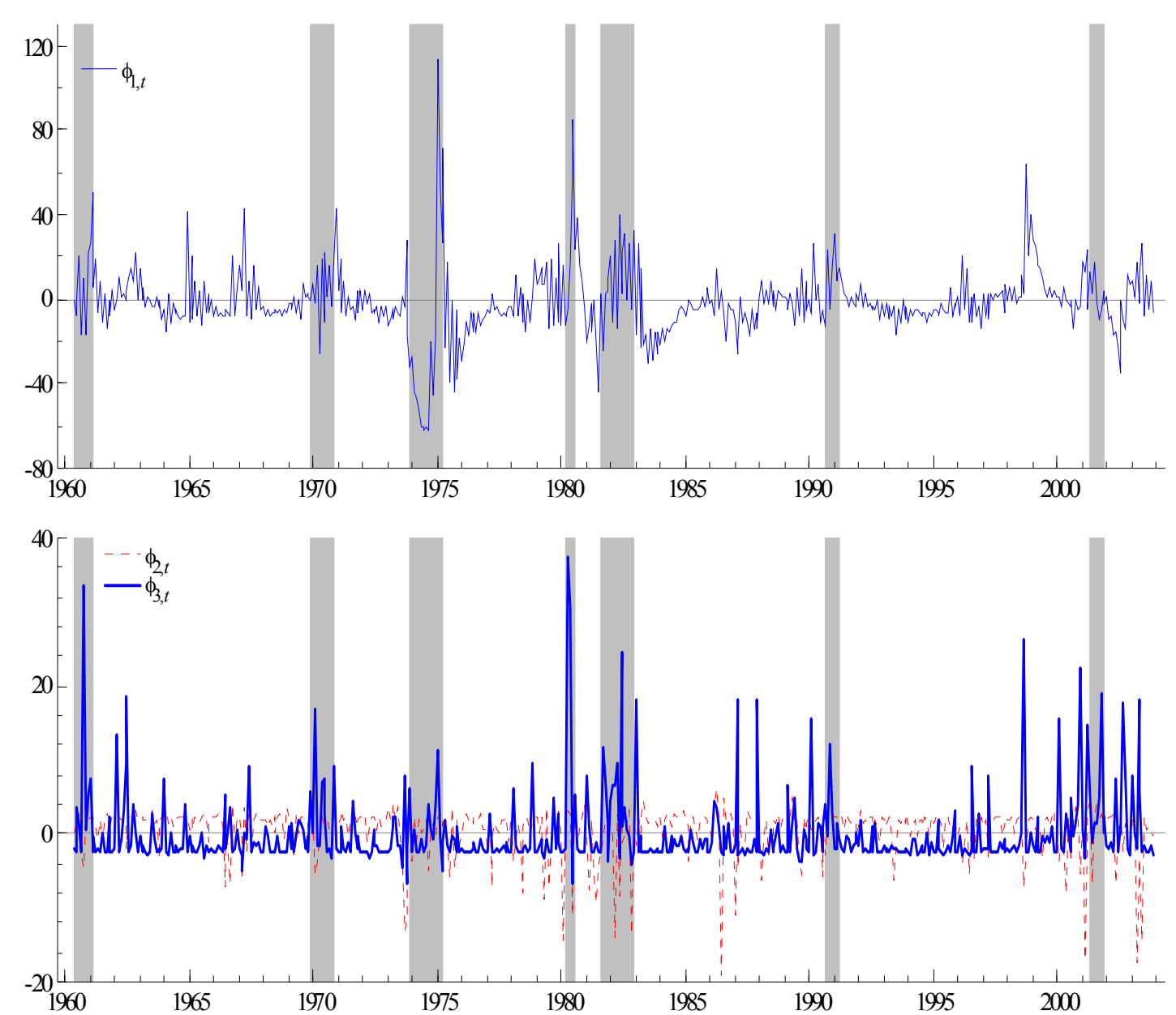

Notes: See figure 1. 
Figure 5: Time-varying correlations between the excess return and the factors

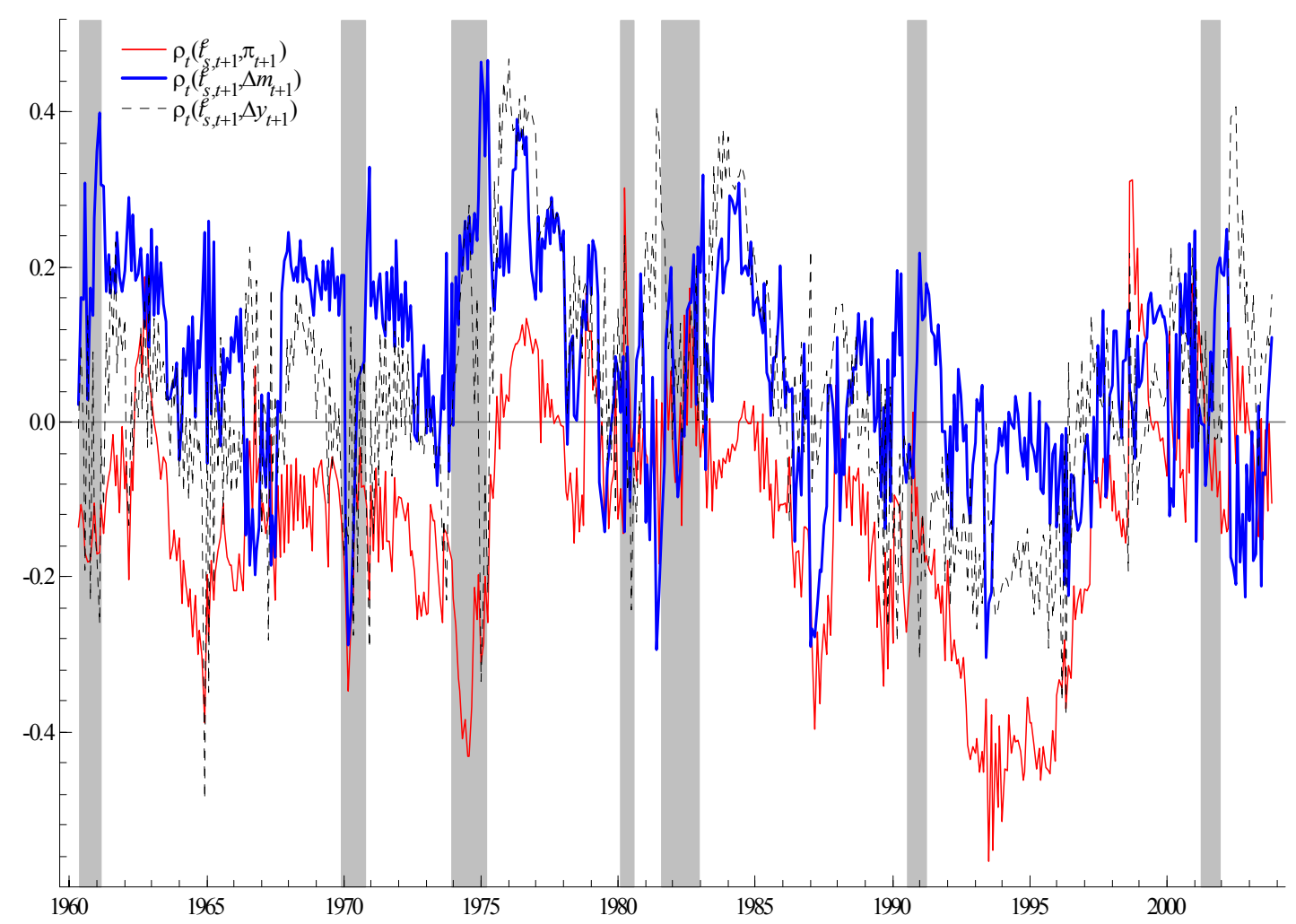

Notes: see Figure 1. 
Figure 6: The contribution to risk of the macroeconomic factors

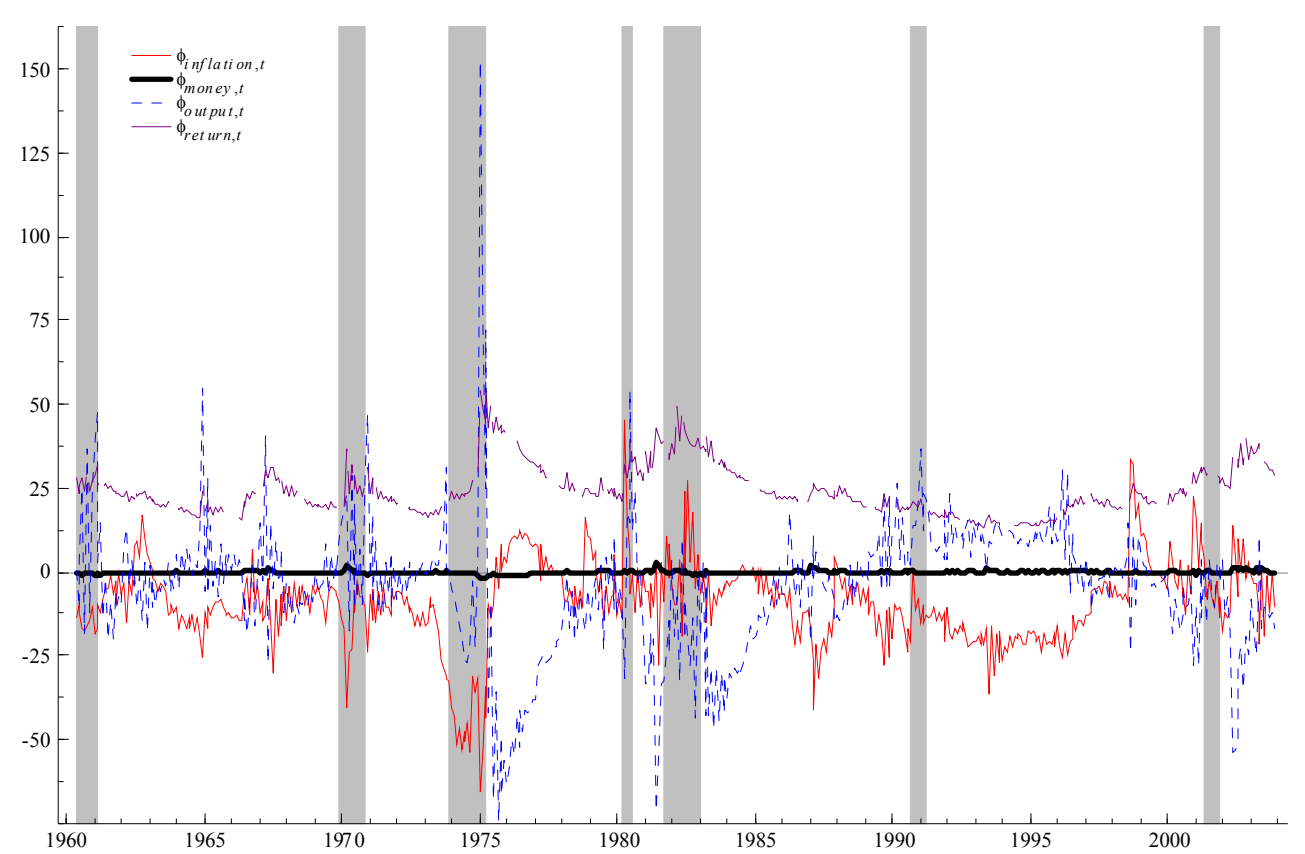

Notes: see Figure 1. 
Figure 7: The risk premium and time-varying correlation between the factors
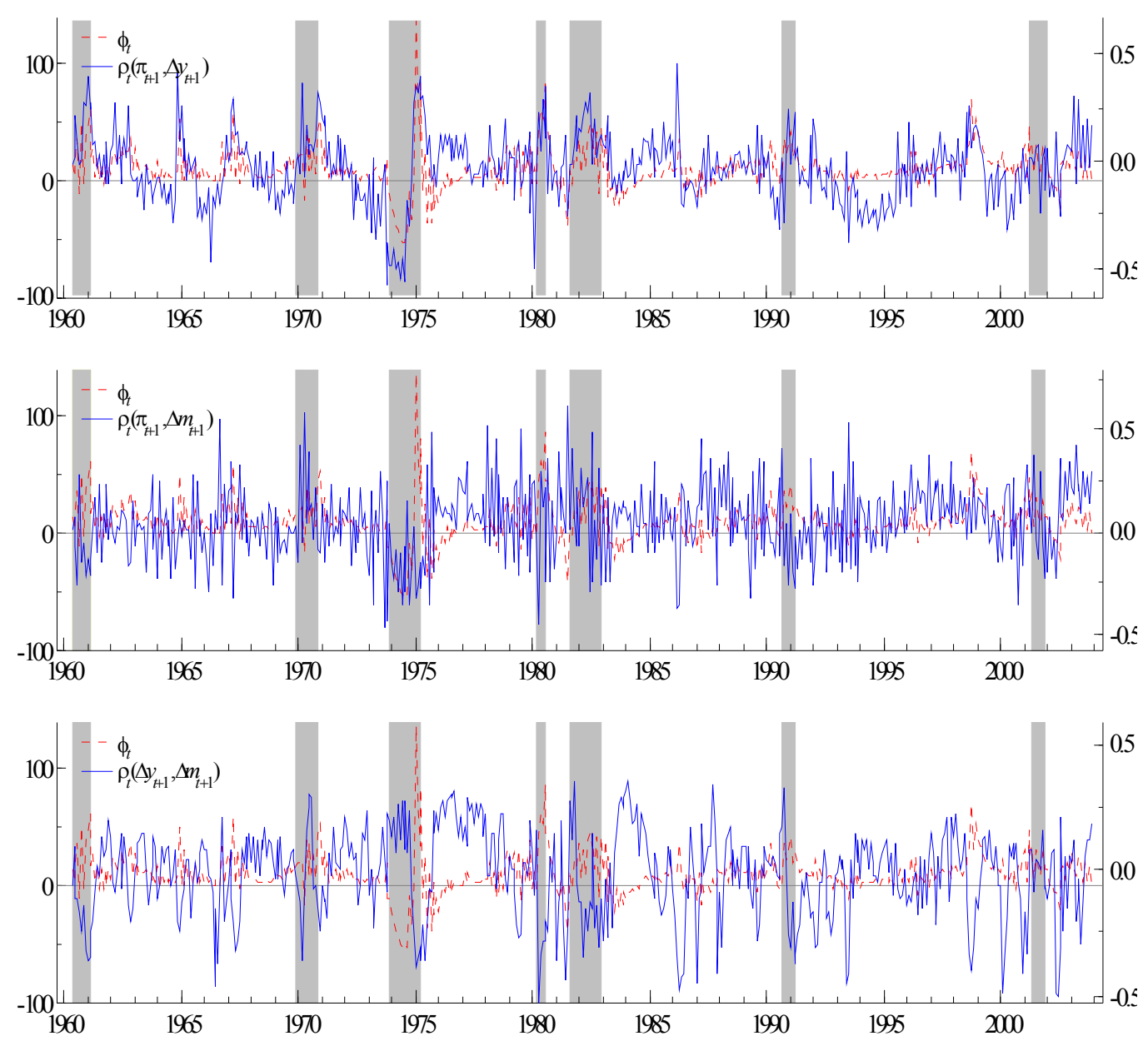
Figure 8: The risk premium per unit of variance

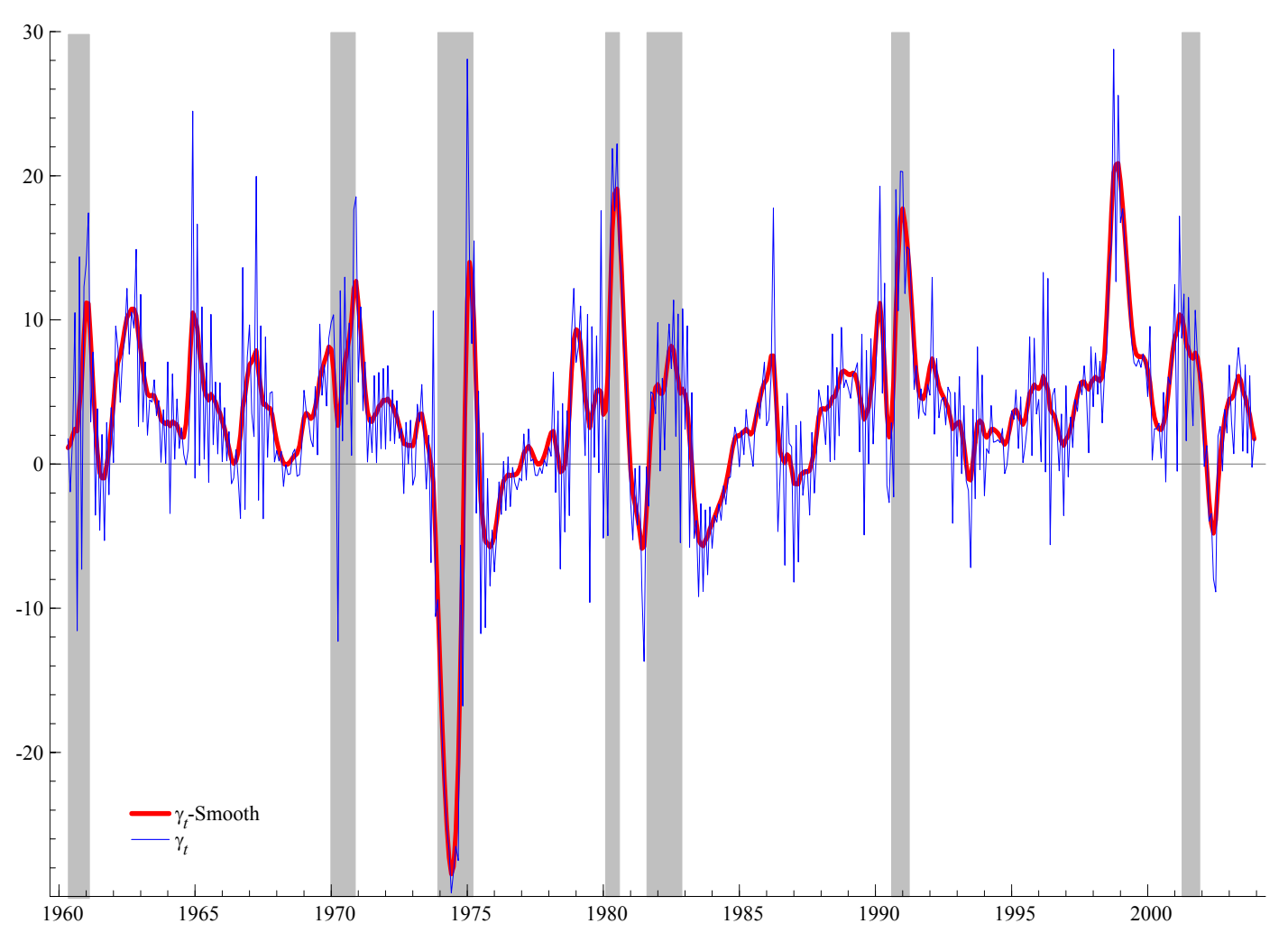

Notes: see Figure $1 \gamma_{t}$ is the risk premium divided by the conditional variance of stock returns in Model 2. 